\title{
Applying System Dynamics of Discrete Supported Track to Analyze the Rail Corrugation Causation on Curved Urban Railway Tracks
}

\author{
Xianxian Yin, ${ }^{1}$ Xiukun Wei $\mathbb{D}^{1},{ }^{1}$ and Haichao Zheng $\mathbb{D}^{2}$ \\ ${ }^{1}$ State Key Laboratory of Rail Traffic Control and Safety, Beijing Jiaotong University, Beijing 100044, China \\ ${ }^{2}$ State Key Laboratory of Subtropical Building Science, South China University of Technology, Guangzhou 510641, China \\ Correspondence should be addressed to Xiukun Wei; 13632196226@163.com
}

Received 6 March 2021; Revised 9 April 2021; Accepted 23 April 2021; Published 11 May 2021

Academic Editor: A. E. Matouk

Copyright (C) 2021 Xianxian Yin et al. This is an open access article distributed under the Creative Commons Attribution License, which permits unrestricted use, distribution, and reproduction in any medium, provided the original work is properly cited.

\begin{abstract}
Urban rail corrugation on curved tracks with small radii causes strong howling during operation, which has been bothering subway operating companies for many years. Therefore, revealing its causes and growth is important for the comfort and safety of subway operation. Current studies believe that the occurrence of rail corrugation is largely due to the resonant vibration of the wheel-rail system. However, little attention has been paid to the key causes of the track resonance and the practical prediction of the occurrence probability of rail corrugation on the certain track. This paper intends to solve these above issues. Firstly, the practical model of predicting the rail corrugation growth is proposed based on the wheel-rail coupling interaction, the key causes of corrugation are investigated, and the sensitivity analysis is carried out, while the corrugation superposition model is introduced to the analyze the corrugation evolution as well as to validate the corrugation growth from the aspect of material friction and wear. Secondly, the impact of the key causes on the initiation and development of the rail corrugation is investigated based on the cosimulation. Finally, case studies validate the proposed theory model and method. The results show that the practical prediction model for the rail corrugation growth proposed in this paper is able to estimate the occurrence possibility of rail corrugation on a specific track, and the superharmonic resonance of the track directly excited by passing vehicles eventually leads to rail corrugation. It is also found that shortwave corrugation develops more rapidly, and adjusting the support stiffness or sleeper spacing leads to fluctuations in the corrugation wavelength and its wear rate.
\end{abstract}

\section{Introduction}

Urban rail transit is an efficient and convenient mode of transportation that can transport a large number of passengers to and from remote urban areas $[1,2]$. The railway system is playing an increasingly important role in meeting urban travel demands [3]. The rapid development of urban transit has brought many positive consequences to the society and economy, as well as unavoidable environmental problems and potential safety hazards [4-7]. Rail corrugation is one of the most troublesome problems in urban rail transit [8]. The design of small radius curve on track will accelerate rail deterioration and increase maintenance cost [9]. In China, rail corrugation is very common in the railway lines, particularly observed in almost all the inner rails of the curved track where the radius is less than $350 \mathrm{~m}$ [10]. Rail corrugation exacerbates vibration and deterioration of vehicle components and causes annoying howling [11], while the failure of the vehicle components will cause great loss [12] and it has been puzzling subway operating companies for many years. Revealing its causes is useful to develop more effective maintenance to inhibit the growth of rail corrugation.

Current studies believe that the occurrence of rail corrugation is largely due to the resonant vibration of the wheel-rail system. Then, how is the resonance of the wheel-rail system excited? How to evaluate the occurrence possibility of corrugation on a specific track simply and quickly? And what are the key factors affecting the formation and development of corrugation? These are the main problems to be answered in this paper. 
In this paper, the system dynamics of discrete supported track is applied to analyze the rail corrugation causation on curved urban railway tracks. The practical prediction model is proposed on the basis of the wheel-rail dynamics to estimate the rail corrugation growth as well as to investigate the key causes of the corrugation. In addition, the superimposed wear of the rail is analyzed to validate the calculated results of the corrugation growth from the aspect of material friction and wear.

\section{Literature Review}

The formation of the rail corrugation is the result of coaction of the wheel-rail interaction, rolling contact mechanics, and the wear properties of wheel-rail materials. The source of complexity often prevents finding the optimal solution [13-18]. Due to the complex and diverse causes of rail corrugation, there is currently no appropriate theoretical system that can give a reasonable explanation for all the rail corrugation observed on railway tracks [19]. In the last decades, the formation mechanism and the develop process of rail corrugation have been extensively studied. In $[20,21]$, all the rail corrugations observed in railway transit were divided into six categories, namely, heavy-haul corrugation, light rail corrugation, track form-specific corrugation, P2 resonance corrugation, rutting corrugation, and roaring rail corrugation. The formation of rail corrugation can be generally attributed to two mechanisms [22-27]: damage mechanism and constant frequency mechanism, while the damage mechanism is considered to be the friction and wear of the material, which is related to the wheel-rail interaction and the tread design of the rail itself [28]. In contrast, the constant frequency mechanism believed that all the categories of rail corrugation were associated with the resonant vibration of the wheel-rail system [20]. Most importantly, more and more researchers now believe that wheel-rail vibration is a critical factor in the formation and growth of rail corrugation.

In recent decades, most of the research studies aiming at the formation mechanism of rail corrugation are done from the perspective of the constant frequency mechanism. There are three important branches in the study of rail corrugation: the first one focuses on the rail corrugation related to the wheelset vibration, the second one concerns the rail corrugation due to the frictional self-excited vibration of wheelset or the track structure, and the third one studies the rail corrugation caused by the resonance of wheel-rail system. In the first branch, the wheelset vibration has a specific impact on rail corrugation formation. Tassilly in [24] revealed that rail corrugation was mainly related to the wheel vibration induced by rail damage, while the effect of the initial rail damage cannot be ignored. The authors in [29] held that the corrugation wavelength was affected by the first-order symmetric and antisymmetric bending vibration frequency of the front wheel. In [30], the cross excitation of wheel-axle torsional vibration and wheel-rail system vertical and lateral vibration causes corrugation on the rail surface. The influence of wheelset interactions on corrugation were discussed in [31], where the wheelset vibration played an essential role in the development of final corrugation. However, the above studies are carried out with comprehensive consideration of the line conditions of the rail corrugated section and are not applicable to all track lines, so the vibration response of the track structure cannot be ignored. In the second branch, the development of rail corrugation was eventually attributed to the self-excited vibration of wheelsets or track structure. For example, in [32], the corrugation growth was investigated and the results proved that the corrugation growth depends on the natural mode of the system. Kurzeck [33] also found that the friction self-excited vibration of the wheel-rail system was closely related to corrugation on the metro with small radius curve in Stuttgart, Germany. In $[34,35]$, the theory that rail corrugation is caused by the friction self-excited vibration of wheelset was proposed. In [36], the generation of rail corrugation was attributed to the phenomenon of the self-excited vibration amplitude of the wheelset being greater than the length of the longitudinal axis of the wheel-rail contact spot. In [8], it considered that the main reason for corrugation appearance was a specific free vibration of the track structure. Nevertheless, selfexcited vibration-based mechanism was generally only applicable to the corrugation on the inner rail with small radius and cannot explain the corrugation occurring on the straight track. In the third branch, the resonance of the wheel-rail system contributed a lot to rail corrugation. In [37], the formation of corrugation was largely due to track resonance. In [38], wheel-rail resonance was the leading cause of corrugation. In [39], the flexibility difference of the rail and sleeper caused rail corrugation. Correa et al. used the corrugation growth as an index to analyze its development [40], and he noted that some resonance between the wheelset and track resulted in corrugation. The thesis in [41] showed that rail corrugation was related to the change in the difference of wheel-rail flexibility, discontinuous rail support, and rail support stiffness. However, the discovery of corrugation associated to wheel-rail system resonance in theory does not mean that corresponding corrugation will inevitably be formed in reality. Sometimes, the generation of corrugation is not only determined by the resonant vibration of the wheel-rail system but also limited by its growth rate.

In reality, some specific wheel-rail dynamics takes effect and leads to the development of the corresponding corrugation with the highest growth rate, while other corrugation is suppressed due to the low growth rate. In [42-45], it was found that the rail absorber could be applied to suppress the growth of rail corrugation due to the pinned-pinned resonance. In [46], the study showed that the growth of rail corrugation was slowed down with the help of the improvement of the material performance of rail. In [47], the corrugation growth was reduced due to the adjustment of the supporting stiffness of rail pad. In addition, the results in [48-50] showed that adjusting the friction coefficient between wheel and rail was also a technical method that could be widely used to reduce the corrugation growth. The above studies are all based on experiments or simulations. However, the research on the key causes of rail corrugation and 
its growth needs to provide strong evidence in theory and practice.

In summary, previous studies proposed the viewpoint that the inherent vibration of wheelsets or track structure results in corrugated wear. However, they did not analyze the key causes and how the inherent vibration was excited, while the investigation of restraining the corrugation growth lacked cogent evidences in theory. This paper concerns the causation and growth of the corrugation on curved tracks with small radii (CTSRs), and the purpose is to propose a practical rail corrugation growth model and discover its key causes in both theory and practice. Firstly, a practical growth model of corrugation based on the vibration theory of wheelrail system is proposed, from which the key causes are extracted and the sensitivity analysis is performed. Secondly, with the aid of the joint-simulation of vehicle-track dynamics and wheel/rail finite element model, the corrugation under different track conditions is calculated. On this basis, this paper proposes that the superharmonic resonance of the curved track directly excited by the passing vehicles eventually leads to corrugation. After that, the corrugation evolution, including the development of the wavelength and corrugation grade, is investigated by using the corrugation superposition model. At the same time, the calculated rail wear is used for the validation of the result of the rail corrugation growth. Finally, a case study is introduced.

The main contribution of this paper lies in the following three aspects. The first one is the proposal of a practical rail corrugation growth model, which can be used to estimate the formation possibility of rail corrugation easily and quickly. The second one lies in that the sensitivity analysis of the track parameters is performed for the new corrugation growth model, where the curve radius and support stiffness are extracted as the two most important factors affecting the growth rate of corrugation. The last one is that a new view on the corrugation formation is introduced, which holds that the vehicle passing excitation caused by track discrete support structure can directly excite the track superharmonic resonance. And the superharmonic resonance eventually leads to rail corrugation. This result is completely different from the existing self-excitation theory and the other-excited theory (the natural vibration of the track structure or wheel-rail system, excited by the track irregularity, finally leads to corrugation). Here, the sleeper spacing and vehicle passing speed are the direct external causes of the resonance of track structure. It is useful for the prevention and maintenance of corrugated wear.

This paper is outlined as follows: the methodology is presented in Section 3. In Section 4, the formation theory of rail corrugation is described. Section 5 focuses on the simulation validation of the corrugation evolution, and Section 6 presents the case study. Finally, the seventh section summarizes some conclusions.

\section{Methodology}

In this section, the practical prediction model of the corrugation growth based on wheel-rail dynamics and the superimposed wear model used for corrugation evolution analysis as well as the validation of corrugation growth are illustrated. After that, the simulation environment and the application of simulation data are stated. Finally, the key factors affecting the growth of rail corrugation are extracted from the derivation process of that, and the sensitivity analysis is carried out by using the cosimulation results.

3.1. Corrugation Growth Prediction Model. The corrugation growth function was proposed by Valdivia [51] and was later improved in $[24,52]$. It can predict the trend of corrugation caused by the continuous development of irregularities at specific positions of tracks after thousands of trains pass by. At present, the wear growth rate has been used to predict the corrugated wear of the rail under various conditions $[40,53-57]$. The model assumes that the wear rate is proportional to the friction force, and the variation of friction force under nominal steady-state condition is proportional to the change of creep. Assuming that the original irregularity wavelength of the line is $L_{k}$, the frequency is $f_{k}$, and the irregularity amplitude is $\Delta z_{k}$. The change rate of irregularity after $n$ trains passing by is expressed as follows [53]:

$$
\frac{\partial \Delta z_{k}(x, n)}{\partial n}=-\frac{k}{2 \rho b v} \Delta P_{\text {frict }}(x, n),
$$

where $k$ is the wear coefficient of the material, $\rho$ is the rail density, $b$ is the length of the semiaxes of the wheel-rail contact patch, $v$ is the train velocity, and $\Delta P_{\text {frict }}(x, n)$ is the fluctuation part of the friction work.

The fluctuation part of the friction work $\Delta P_{\text {frict }}(x, n)$ can be expresses as follows [8]:

$$
\Delta P_{\text {frict }}(x, n)=v\left(\Delta T_{y} C_{y}+T_{y} \Delta C_{y}\right),
$$

where $T_{y}$ is the lateral creep force and $C_{y}$ represents the lateral creepage.

Then, equation (1) can be shown as follows:

$$
\frac{\partial \Delta z_{k}(x, n)}{\partial n}=\lambda_{k} \Delta z_{k}(x, n),
$$

where $\lambda_{k}$ is the characteristic variable of equation (3), and it is a complex number that depends on the state variables of the system.

The growth model of corrugation $G_{c}$ on position $x$ is the real part of $\lambda_{k}$ and can be derived as follows. The detailed derivation process is explained in $[8,31]$, and we will not explain it here. In this paper, the growth prediction function 
is simplified for corrugation on curved rail with small radii, and the result is validated by simulation:

$$
G_{c}=\frac{k}{4 \rho b d}\left(3 N \cdot \frac{\partial T_{y}}{\partial N}+c \cdot \frac{\partial T_{y}}{\partial c}\right) \frac{T_{y, 0} \cdot\left(\partial T_{y} / \partial C_{y}\right)\left(U_{y} / r_{i}\right)^{2}+C_{y, 0}}{\left(1+U_{z}(3 N / 2 d)\right)\left[1+\left(\left(\partial T_{y} / \partial C_{y}\right)\left(U_{y} / r_{i}\right)\right)^{2}\right]},
$$

where $N$ is the normal force of the wheel-rail contact, $T_{y, 0}$ are the actual part of the lateral creep force, $C_{y, 0}$ represent the real part of the lateral creepage, $U_{y}$ and $U_{z}$ are the lateral and vertical track receptance, respectively, and $c$ is parameters related to the wheel-rail contact patch. See Table 1 for other symbols.

The larger the amplitude of $G_{c}$ is, the more likely that corrugation is appearing on the line. It is known that positive values above 0.01 correspond to situations where rail corrugation wear certainly appears [52]. Thus, the frequency corresponding to the maximum amplitude is one of the main vibrations that generates the wave.

The above model for the calculation of rail corrugation growth is a generalized calculation model, which is not suitable for direct estimation of rail corrugation growth in metro, and the parameters are complicated and unintuitive. Therefore, the main influencing factors are highlighted to improve the above corrugated growth model. As a result, a more intuitive calculation model for the estimation of the corrugation growth is obtained. Firstly, the corrugation growth model at a specific position $x$ can be described as follows:

$$
G_{c}=K_{0} K_{1} K_{2} K_{3}
$$

where $K_{0}$ is a constant as the material coefficient of rail, $K_{1}$ indicates the fluctuation of wheel-rail creep force, $K_{2}$ is the influencing of rail vertical dynamics, and $K_{3}$ is the influencing of rail lateral dynamics. And they are defined as follows:

$$
\begin{aligned}
K_{0} & =\frac{k}{4 \rho}, \\
K_{1} & =3 N \cdot \frac{\partial T_{y}}{\partial N}+c \cdot \frac{\partial T_{y}}{\partial c}, \\
K_{2} & =\frac{1}{\mathrm{~d}\left(1+U_{z}(3 N / 2 d)\right)} \\
K_{3} & =\frac{T_{y, 0} \cdot\left(\partial T_{y} / \partial C_{y}\right)\left(1 /\left(r_{i}\right)^{2}\right) U_{y}^{2}+C_{y, 0}}{b\left[1+\left(\left(\partial T_{y} / \partial C_{y}\right)\left(1 / r_{i}\right) U_{y}\right)^{2}\right] .}
\end{aligned}
$$

Considering Hertz's nonlinear elastic contact theory, the partial derivative from creep force $T_{y}$ to wheel track normal contact force $N$, contact spot size $c$ and lateral creepage $C_{y}$, and the vertical force between wheel and rail as well as the maximum lateral creepage can be determine as [8]

$$
\begin{aligned}
\frac{\partial T_{y}}{N} & =-\mu \operatorname{sgn}\left(C_{y}\right)\left(\frac{C_{y}}{C_{y, \max }}\right)^{2}\left[3-2 \frac{\left|C_{y}\right|}{C_{y, \max }}\right], \\
\frac{\partial T_{y}}{c} & =\frac{3 \mu N}{c C_{y, \max }} \operatorname{sgn}\left(C_{y}\right)\left(1-\frac{\left|C_{y}\right|}{C_{y, \max }}\right)^{2}, \\
\frac{\partial T_{y}}{C_{y}} & =-\frac{3 \mu N}{C_{y, \max }}\left(1-\frac{\left|C_{y}\right|}{C_{y, \max }}\right)^{2}, \\
N & =\left[\frac{1}{G} \mathrm{~d}\right]^{(3 / 2)}, \\
C_{y, \max } & =\frac{3 \mu N}{M_{s} a b C_{22}} .
\end{aligned}
$$

where $\mu$ is the frictional coefficient, $G$ is the wheel-rail contact constant, $M_{s}$ is the shear modulus of wheel-rail material, $a, b$ is the length of the long and short semiaxis of the wheel-rail contact area, respectively, $C_{22}$ is the Kalker creep coefficient, and its value depends on the ratio of $a, b$.

As the fluctuation of creep force depends on the fluctuation of normal force, contact patch, and creepage [31], $K_{1}-K_{3}$ can be further simplified as follows:

$$
K_{1}=3 \mu T^{2}(3-2 T) N-M_{s}(1-T)^{2} C_{22} a b,
$$

where $T$ is the ratio of creepage to maximum creepage:

$$
K_{2}=\frac{1}{\mathrm{~d}\left(1+(3 / 2) G^{-(3 / 2)} \mathrm{d}^{(1 / 2)} U_{z}\right)} \text {. }
$$

Dynamic calculation shows the magnitude of $G^{-(3 / 2)} \mathrm{d}^{(1 / 2)} U_{z}$ is $10^{4}$, so $K_{2}$ can be further simplified as

$$
K_{2}=\frac{2}{3} G^{(3 / 2)} \frac{1}{\mathrm{~d}^{(3 / 2)} U_{z}} \text {. }
$$

As the creep force on the small radius curve is saturated, that is, $T_{y, 0}=\mu N$, then $K_{3}$ can be further simplified. And before that, the following problem should be solved:

$$
1+\left(\frac{\partial T_{y}}{\partial C_{y}} \frac{1}{r_{i}} U_{y}\right)^{2}=1+\left[M_{s} C_{22}(1-T)^{2} a b r_{i}^{-1} U_{y}\right]^{2} .
$$

Note that the dynamic calculation shows the magnitude of $\left[M_{s} C_{22}(1-T)^{2} a b r_{i}^{-1} U_{y}\right]^{2}$ is $10^{-4}$, so

$$
1+\left(\frac{\partial T_{y}}{\partial C_{y}} \frac{1}{r_{i}} U_{y}\right)^{2} \approx 1
$$


Then, $K_{3}$ can be reduced as follows:

$$
\begin{aligned}
K_{3}= & -\mu M_{s} C_{22}(1-T)^{2} r_{i}^{-2} G^{-(3 / 2)} a d^{(3 / 2)} U_{y}^{2} \\
& +3 \mu T M_{s}^{-1} C_{22}^{-1} G^{-(3 / 2)}\left(a b^{2}\right)^{-1} \mathrm{~d}^{(3 / 2)} .
\end{aligned}
$$

Finally, the corrugation growth model in equation (5) can be derived as follows:

$$
\begin{aligned}
G_{c}= & K_{0} \cdot Q_{Z} \cdot U_{z}^{-1} \cdot\left(Q_{N} \cdot N+Q_{A} \cdot a b\right) \\
& \cdot\left[Q_{Y} \cdot a U_{y}^{2}+Q_{r z} \cdot\left(a b^{2}\right)^{-1}\right], \\
Q_{Z}= & \frac{2}{3} G^{(3 / 2)}, \\
Q_{N}= & 3 \mu T^{2}(3-2 T), \\
Q_{A}= & -M_{s}(1-T)^{2} C_{22}, \\
Q_{Y}= & -\mu M_{s} C_{22}(1-T)^{2} r_{i}^{-2} G^{-(3 / 2)}, \\
Q_{r z}= & 3 \mu T M_{s}^{-1} C_{22}^{-1} G^{-(3 / 2)},
\end{aligned}
$$

where $Q_{Z}$ indicates the factor of vertical vibration of track structure, $Q_{N}$ indicates the factor of wheel-rail normal contact, $Q_{A}$ indicates the factor of wheel-rail contact patch, $Q_{Y}$ indicates the factor of lateral vibration of track structure, and $Q_{r z}$ indicates the factor of wheel-rail contact deformation.

The correlation coefficients in the corrugated growth model are calculated by referring to the dynamic parameters and relevant empirical parameters of wheel-rail materials (China metro rail CHN60 and wheelset UICS1002). Therefore, rail corrugation growth model is finally simplified as follows:

$$
\begin{aligned}
G_{c}= & \frac{1.882}{U_{z}} \cdot\left(1.344 N-3.4923 \times 10^{10} a b\right) \\
& \cdot\left(-8.991 \times 10^{-4} a U_{y}^{2}+0.2458 \times 10^{-25} \frac{1}{a b^{2}}\right) .
\end{aligned}
$$

Remark 1. This paper introduces a practical prediction model of rail corrugation growth as shown in equation (15). It highlights the influence of the rail receptance $\left(U_{z}, U_{y}\right)$ and also considers the wheel-rail contact dynamics $(N, a, b)$. In the following, the curved-track receptance $\left(U_{z}, U_{y}\right)$ is deduced and analyzed to extract the key track parameters associated to the corrugation growth on curve.
3.1.1. Rail Receptance Calculation Model. The rail is simplified as a curved Euler-Bernoulli beam with equal distance and scattered point support as shown in Figure 1(a). All deformations are assumed to be so small that the linear theory is applied. Assuming that the curved beam has a constant cross section, the warpage resistance is negligible. When the wheel passes by the track at the speed $v$, the resonance wheel-rail force with angle frequency $w_{f}$ is generated due to the influence of discrete sleepers. Applying a unit resonance force $e^{i w_{f} t}$ to the vertical and lateral directions of the rail, the lateral and vertical vibration equations of the curved beam are obtained as follows [58]:where $u_{y}$ and $u_{z}$ are the rail displacements in the $y$ and $z$ directions, respectively, $\varphi$ is the torsional angle around the $x$-axis of a specific point at time $t, I_{y}$ and $I_{z}$ are the area moment of inertia of the $y$-axis and $z$-axis, respectively, $I_{d}$ is rail section torsional constant, and $E$ is elastic modulus. And $k_{y}, k_{z}, c_{y}$, and $c_{z}$ represent the stiffness and damping of the track structure in the $y$ and $z$ directions, respectively. See Table 1 for other symbols.

$$
\begin{gathered}
E I_{z}\left(\frac{\partial^{4} u_{y}}{\partial x^{4}}+\frac{1}{R^{2}} \frac{\partial^{2} u_{y}}{\partial x^{2}}\right)+m \frac{\partial^{2} u_{y}}{\partial t^{2}}+k_{y} u_{y}+c_{y} \frac{\partial u_{y}}{\partial t}=e^{i w_{f} t} \\
E I_{y} \frac{\partial^{4} u_{z}}{\partial x^{4}}-\frac{M_{s} I_{d}}{R^{2}} \cdot \frac{\partial^{2} u_{z}}{\partial x^{2}}-\frac{E I_{y}+M_{s} I_{d}}{R} \cdot \frac{\partial^{2} \varphi}{\partial x^{2}}+m \frac{\partial^{2} u_{z}}{\partial t^{2}} \\
+k_{z} u_{z}+c_{z} \frac{\partial u_{z}}{\partial t}=e^{i w_{f} t}
\end{gathered}
$$

The deformation of equation (17) is derived with the help of the bending and torsion characteristics of the curved beam shown in Figure 1(b), where the torsion and vertical bending of curved beams are coupled with each other. When the beam microsegment $O A$ has a slight bending angle $\theta$ around the $y$ axis in the $O$ section, the $A$ section produces a torsion angle, and its meridian changes from $D A$ to $D A^{\prime}$, then

$$
\varphi=\frac{A A^{\prime}}{R}=\frac{C A \cdot \theta_{y \theta}}{R}=\operatorname{tg} \mathrm{d} \psi \cdot \theta_{y \theta},
$$

where

$$
\begin{aligned}
\theta_{y \theta} & =\theta \cdot \frac{O B}{C A}=\theta \cdot \frac{O^{\prime} A}{C A}=\theta \cdot \cos \mathrm{d} \psi, \\
\theta & =\frac{\mathrm{d} u_{z}}{\mathrm{~d} x} .
\end{aligned}
$$

For small enough beam segments,

$$
\varphi=\frac{1}{R} \frac{\mathrm{d} u_{z}}{\mathrm{~d} x} \text {. }
$$



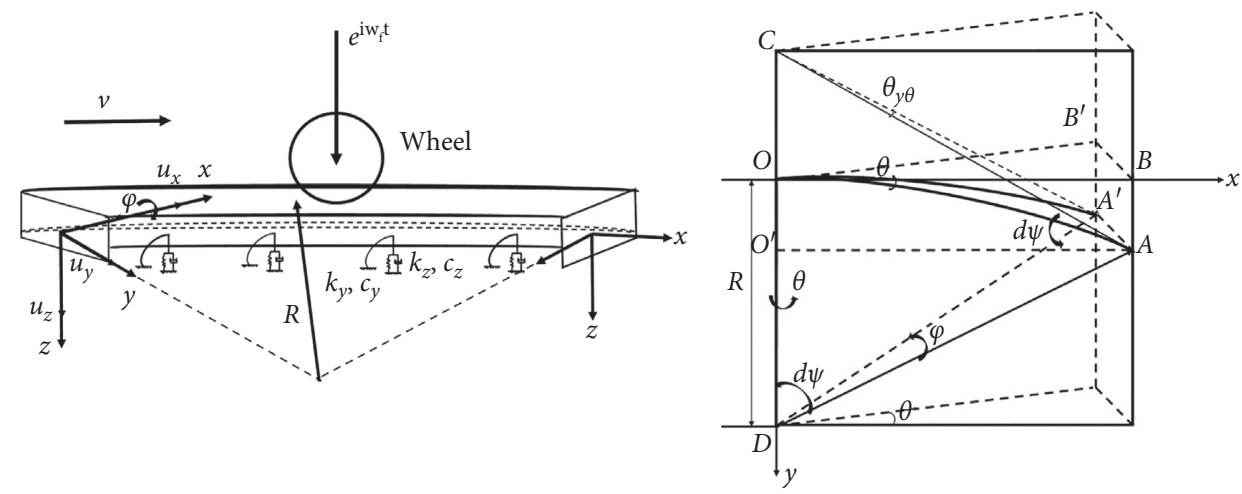

(a)

(b)

FIGURE 1: The geometric model for vibration analysis of curved beams: (a) mechanical model of curved beam; (b) geometric coupling of bending and torsion deformation.

TABLE 1: Symbols used in calculation.

\begin{tabular}{|c|c|}
\hline Symbol & Definition \\
\hline$k$ & Wear coefficient of material \\
\hline$\rho$ & Material density \\
\hline$b$ & Long semi-axis of the modified wheel-rail contact ellipse \\
\hline$N$ & Normal force of the wheel-rail contact \\
\hline$d$ & Elastic deformation between the wheel and rail \\
\hline$T_{y}$ & Lateral creep force \\
\hline$T_{y, 0}^{y}$ & Actual part of the lateral creep force \\
\hline$c$ & Modified contact ellipse coefficient \\
\hline$C_{y}$ & Lateral creepage \\
\hline$C_{y, 0}^{\prime}$ & Actual part of lateral creepage \\
\hline$v$ & Train passing speed \\
\hline$f$ & Wheel rolling frequency \\
\hline$G_{c}$ & Corrugation formation function \\
\hline$r_{i}$ & Instantaneous rolling radius of each wheel \\
\hline$M_{z}$ & Torque around the $z$-axis \\
\hline$C_{x}^{2}, C_{y}, \xi_{z}$ & Longitudinal, transverse, and spin creepage \\
\hline$U_{y}$ & Lateral vibration displacement responses of track \\
\hline$U_{z}^{y}$ & Vertical vibration displacement responses of track \\
\hline$u_{x}, u_{y}, u_{z}$ & The rail displacement in $x, y, z$ direction \\
\hline$\varphi$ & Rail torsional angle around $z$-axis \\
\hline$m$ & Reference mass in unit length of rail \\
\hline$A$ & Rail section area \\
\hline$I_{d}$ & Rail section torsional constant \\
\hline$I_{0}$ & Part polar moment of inertia \\
\hline$E$ & Elastic modulus \\
\hline$M_{s}$ & Shear modulus \\
\hline$I_{y}, I_{z}$ & The area moment of inertia of $y$-axis and $z$-axis \\
\hline$w$ & Excitation circle frequency \\
\hline $\mathrm{d}_{f}$ & Sleeper spacing \\
\hline$T_{x}$ & Longitudinal creep forces \\
\hline$l^{x}$ & Track gauge \\
\hline
\end{tabular}


By substituting it into the vertical vibration equation of curved beam, we can get

$$
\begin{gathered}
E I_{y} \frac{\partial^{4} u_{z}}{\partial x^{4}}-\frac{E I_{y}+M_{s} I_{d}}{R^{3}} \cdot \frac{\partial^{3} u_{z}}{\partial x^{3}}-\frac{M_{s} I_{d}}{R^{2}} \cdot \frac{\partial^{2} u_{z}}{\partial x^{2}}+m \frac{\partial^{2} u_{z}}{\partial t^{2}} \\
+k_{z} u_{z}+c_{z} \frac{\partial u_{z}}{\partial t}=e^{i w_{f} t} .
\end{gathered}
$$

In order to solve the differential equations in frequency domain, Fourier transform is applied with respect to time to equation (16) and equation (21) as follows [59]:

$$
\begin{gathered}
E^{*} I_{z}\left(\frac{\partial^{4} u_{y}^{*}}{\partial x^{4}}+\frac{1}{R^{2}} \frac{\partial^{2} u_{y}^{*}}{\partial x^{2}}\right)-m w^{2} u_{y}^{*}+k_{y}^{*} u_{y}^{*} \\
=\frac{1}{v} e^{i\left(\left(w_{f}-w\right) / v\right)\left(x-x_{0}\right)}, \\
E^{*} I_{y} \frac{\partial^{4} u_{z}^{*}}{\partial x^{4}}-\frac{E^{*} I_{y}+M_{s}^{*} I_{d}}{R^{3}} \cdot \frac{\partial^{3} u_{z}^{*}}{\partial x^{3}}-\frac{M_{s}^{*} I_{d}}{R^{2}} \cdot \frac{\partial^{2} u_{z}^{*}}{\partial x^{2}} \\
\quad-m w^{2} u_{z}^{*}+k_{z}^{*} u_{z}^{*}=\frac{1}{v} e^{i\left(\left(w_{f}-w\right) / v\right)\left(x-x_{0}\right)},
\end{gathered}
$$

where $*$ indicates the expressions of the variables in the frequency domain, $u_{y}^{*}$ and $u_{z}^{*}$ are the displacement of point $x$ in $y, z$ direction in frequency domain, $E^{*}=E(1+i \eta)$ and $M_{s}^{*}=M_{s}(1+i \eta)$ is the elastic modulus and shear modulus considering the damping of rail material, in which the $\eta$ is the damping loss factor of the rail, $k_{y}^{*}$ and $k_{z}^{*}$ represent the lateral and vertical support complex stiffness of the fastener, and $k_{y}^{*}=k_{y}+i c_{y} w, k_{z}^{*}=k_{z}+i c_{z} w$, where $w$ is the angular frequency of the track vibration.

In this paper, the generalized wave number method in [58] is introduced to solve the frequency response function of curved rail beam. According to the frequency domain mathematical mode superposition method, the dynamic response of rail beam can be obtained as follows:

$$
u^{*}\left(x, \kappa, w_{f}\right)=\sum_{n=-N}^{n=N} C_{n}\left(\kappa, w_{f}\right) V_{n}^{*}\left(x, \kappa, w_{f}\right),
$$

where

$$
\begin{aligned}
u^{*}\left(x, \kappa, w_{f}\right) & =\left[u_{y}^{*}\left(x, \kappa, w_{f}\right), u_{z}^{*}\left(x, \kappa, w_{f}\right)\right]^{T}, \\
C_{n}\left(\kappa, w_{f}\right) & =\left[B_{n}^{y}\left(\kappa, w_{f}\right), B_{n}^{z}\left(\kappa, w_{f}\right)\right]^{T}, \\
V_{n}^{*}\left(x, \kappa, w_{f}\right) & =e^{i\left(\xi_{n}-\kappa\right) x}, \\
\xi_{n} & =\frac{2 \pi n}{\mathrm{~d}_{f}},
\end{aligned}
$$

where $V_{n}^{*}\left(x, \kappa, w_{f}\right)$ is the mathematical mode of rail beam in frequency domain, and $2 N+1$ modes are considered in this calculation. $C_{n}\left(\kappa, w_{f}\right)$ is the modal coordinate function vector, in which $B_{n}^{y}\left(\kappa, w_{f}\right), B_{n}^{z}\left(\kappa, w_{f}\right)$ is the mathematical mode coordinate function of rail beam corresponding to the transverse and vertical displacement modes in frequency domain. $\kappa$ is the generalized wave number [60], and $\kappa=\left(\left(w-w_{f}\right) / v\right)$.

Applying equation (24) into equation (22) and equation (23) and performing integral processing on it in the basic length $\left(x \in\left[0, d_{f}\right]\right)$, the equations corresponding to the $m$ th-order mode of the rail is

$$
\begin{gathered}
E^{*} I_{z} \mathrm{~d}_{f}\left(\xi_{m}-\kappa\right)^{4} B_{m}^{y}-\frac{E^{*} I_{z}}{R^{2}} \mathrm{~d}_{f}\left(\xi_{m}-\kappa\right)^{2} B_{m}^{y}-m w^{2} \mathrm{~d}_{f} B_{m}^{y} \\
+\mathrm{d}_{f} k_{y}^{*} B_{m}^{y}=\frac{1}{v} e^{i \kappa x_{0}} \int_{0}^{\mathrm{d}_{f}} e^{-i \xi_{m} x} \mathrm{~d} x \\
E^{*} I_{y} \mathrm{~d}_{f}\left(\xi_{m}-\kappa\right)^{4} B_{m}^{z}+\frac{E^{*} I_{y}+M_{s}^{*} I_{d}}{R^{3}} \mathrm{~d}_{f} i\left(\xi_{m}-\kappa\right)^{3} B_{m}^{y} \\
+\frac{M_{s}^{*} I_{d}}{R^{2}} \mathrm{~d}_{f}\left(\xi_{m}-\kappa\right)^{2} B_{m}^{y}-m w^{2} \mathrm{~d}_{f} B_{m}^{y} \\
+\mathrm{d}_{f} k_{z}^{*} B_{m}^{y}=\frac{1}{v} e^{i \kappa x_{0}} \int_{0}^{d_{f}} e^{-i \xi_{m} x} \mathrm{~d} x
\end{gathered}
$$

where $\mathrm{d}_{f}$ is the sleeper spacing.

By sorting out equations (26) and (27), we can get

$$
M\left(\kappa, w_{f}\right) D\left(\kappa, w_{f}\right)=P\left(\kappa, w_{f}\right)
$$

where

$$
\begin{aligned}
D\left(\kappa, w_{f}\right)= & {\left[B_{-N}^{y}, \ldots, B_{N}^{y}, B_{-N}^{z}, \ldots, B_{N}^{z}\right]^{T}, } \\
M\left(\kappa, w_{f}\right)= & \operatorname{diag}\left(\alpha_{-N}^{y}, \ldots, \alpha_{N}^{y}, \alpha_{-N}^{z}, \ldots, \alpha_{N}^{z}\right), \\
\alpha_{m}^{y}= & E^{*} I_{z} \mathrm{~d}_{f}\left(\xi_{m}-\kappa\right)^{4}-\frac{E^{*} I_{z}}{R^{2}} \mathrm{~d}_{f}\left(\xi_{m}-\kappa\right)^{2} \\
& -m w^{2} \mathrm{~d}_{f}+\mathrm{d}_{f} k_{y}^{*}, \\
\alpha_{m}^{z}= & E^{*} I_{y} \mathrm{~d}_{f}\left(\xi_{m}-\kappa\right)^{4}+\frac{E^{*} I_{y}+M_{s}^{*} I_{d}}{R^{3}} \mathrm{~d}_{f} i\left(\xi_{m}-\kappa\right)^{3} \\
& +\frac{M_{s}^{*} I_{d}}{R^{2}} \mathrm{~d}_{f}\left(\xi_{m}-\kappa\right)^{2}-m w^{2} \mathrm{~d}_{f}+\mathrm{d}_{f} k_{z}^{*},
\end{aligned}
$$

where $P\left(\kappa, w_{f}\right)$ is the $(4 N+2) \times 1$ order column vector with only two nonzero elements, and the $j$-th element $P(j, 1)$ in the matrix can be expressed in MATLAB language as

$$
P(j, 1)= \begin{cases}\frac{\mathrm{d}_{f}}{v} e^{i \kappa x_{0}} & (j=N+1), \\ \frac{\mathrm{d}_{f} e^{i \kappa x_{0}}}{v} & (j=3 N+2), \\ 0 & (j=\text { others }) .\end{cases}
$$


This paper considers the steady-state fixed load, so $v=0$ and $x=x_{0}$, then substituting equation (28) into equation
(24), and the receptance of the curved rail beams corresponding to the $m$ th-order mode is obtained as follows:

$$
\begin{aligned}
& U_{y}=\frac{1}{2 \pi} \cdot \frac{e^{i \xi_{m} x}}{E^{*} I_{z}\left(\xi_{m}-\kappa\right)^{4}-\left(E^{*} I_{z} / R^{2}\right)\left(\xi_{m}-\kappa\right)^{2}+k_{y}^{*}-m w^{2}}, \\
& U_{z}=\frac{1}{2 \pi} \cdot \frac{e^{i \xi_{m} x}}{E^{*} I_{y}\left(\xi_{m}-\kappa\right)^{4}+\left(\left(E^{*} I_{y}+M_{s}^{*} I_{d}\right) / R^{3}\right) i\left(\xi_{m}-\kappa\right)^{3}+\left(\left(M_{s}^{*} I_{d}\right) / R^{2}\right)\left(\xi_{m}-\kappa\right)^{2}+k_{z}^{*}-m w^{2}} .
\end{aligned}
$$

Remark 2. Equation (31) and equation (32) show that track receptance $\left(U_{z}, U_{y}\right)$ depends on the track material parameters $\left(E, M_{s}, I_{y}, I_{z}, I_{d}\right)$, support parameters under rail $\left(k_{z}, k_{y}, c_{z}, c_{y}\right)$, and the angular frequency of the external excitation $\left(w_{f}\right)$. For a specified track, the track material properties are fixed, while the supporting stiffness and damping meets the design requirements of the damping ratio. The external excitation considered in this paper only refers to the vehicle passing excitation, so $w_{f}=\left(v / \mathrm{d}_{f}\right)$. Therefore, the rail receptance (equation (31) and equation (32)) at a certain position $x$ can finally be regarded as a function of the response frequency $w$, while its amplitude depends on the track structure variables $R, d_{f}, k_{z}$.

3.1.2. Sensitivity Analysis of Corrugation Growth Model. The material parameters of the CHN60 rail of the metro track are introduced into equation (28) and equation (31) for model simplification, and the obtained rail receptance is substituted into equation (15) for the new corrugation growth model as follows:

$$
\begin{aligned}
G_{c}= & \frac{1}{e^{i \sigma x}} \cdot\left[1.18 \times 10^{7} \sigma^{2}\left(6.624 \sigma^{2}-\frac{6.8}{R^{3}} \sigma i+\frac{0.17}{R^{2}}\right)+11.82 k_{z}^{*}-7.15 \times 10^{2} w^{2}\right] \cdot\left(1.344 N-3.4923 \times 10^{10} a b\right) \\
& \cdot\left[\frac{-8.991 \times 10^{-4} a e^{i 2 \sigma x}}{\left[4.16 \times 10^{7} \sigma^{2}\left(\sigma^{2}-R^{-2}\right)+6.28 k_{y}^{*}-3.8 \times 10^{2} w^{2}\right]^{2}}+0.2458 \times 10^{-25} \frac{1}{a b^{2}}\right]
\end{aligned}
$$

where $\sigma=6.28\left(m / \mathrm{d}_{f}\right)$ and $m$ is the modal order.

It shows that the corrugation growth $G_{c}$ can be described as frequency $f=(w / 2 \pi)$ dependent function, where the amplitude is limited by the contact parameters $N, a, b$, track parameters of $R, d_{f}$, and $k_{z}$. The fluctuation of variables $a, b, N, U_{z}, U_{y}$ with track position $x$ is calculated as shown in Figure 2.

The discontinuity of railway track leads to significant fluctuation of the model variables, especially the rail receptance. It is found that the values of these variables fluctuate periodically along the running direction, and the period is about the length of sleeper spacing. Additionally, the track receptance fluctuates significantly with the position of the track as shown in Figure 2(b).

For the rail corrugation on curved-track with small radii, several factors affect the corrugation growth to some extent. In this paper, the dominant factors include the curve radius $R$, support stiffness $k_{z}$, and the sleeper spacing $d_{f}$. To investigate the relationship between the corrugation growth and each of these factors, the sensitivity analysis of the three track parameters is performed for the new corrugation growth model in equation (33). The contributions of these three factors to the corrugation growth are shown in Figure 3.
As presented in Figure 3(a), corrugation growth $G_{c}$ can be described as an exciting frequency dependent function. This is because, according to the equation of the rail receptance $U_{z}$ and $U_{y}$ derived by us, the rail receptance is a simple harmonic wave, whose amplitude and period change with these three factors. In addition, the curve radius plays the dominant role in the growth of corrugated wear. With the increase of the curve radius, the value of $G_{c}$ decreases first and then decreases rapidly after the radius is greater than $600 \mathrm{~m}$. At the same time, the corrugation passing frequency decreases linearly. This can be explained as the large dynamic effect of the wheel-rail system on a curve with a small radius, which is easier to form rail corrugation and accelerate its development. And equation (33) also shows that $G_{c}$ is approximately inversely proportional to the power of the radius of curved-track. Therefore, the corrugated wear rate decreases as the curvature increases. Figure 3(b) shows that the value of $G_{c}$ descends on the increase of the support stiffness. It indicates that the support stiffness $k_{z}$ has a great impact on the growth of corrugated wear as shown in equation (33). That is, $G_{c}$ is in direct proportional to $k_{z}$ but inversely proportional to the square of $k_{y}$. Besides that, the corrugation frequency continues to decrease along with the increase of $k_{z}$, while the rate of decrease slows down when $k_{z}$ 

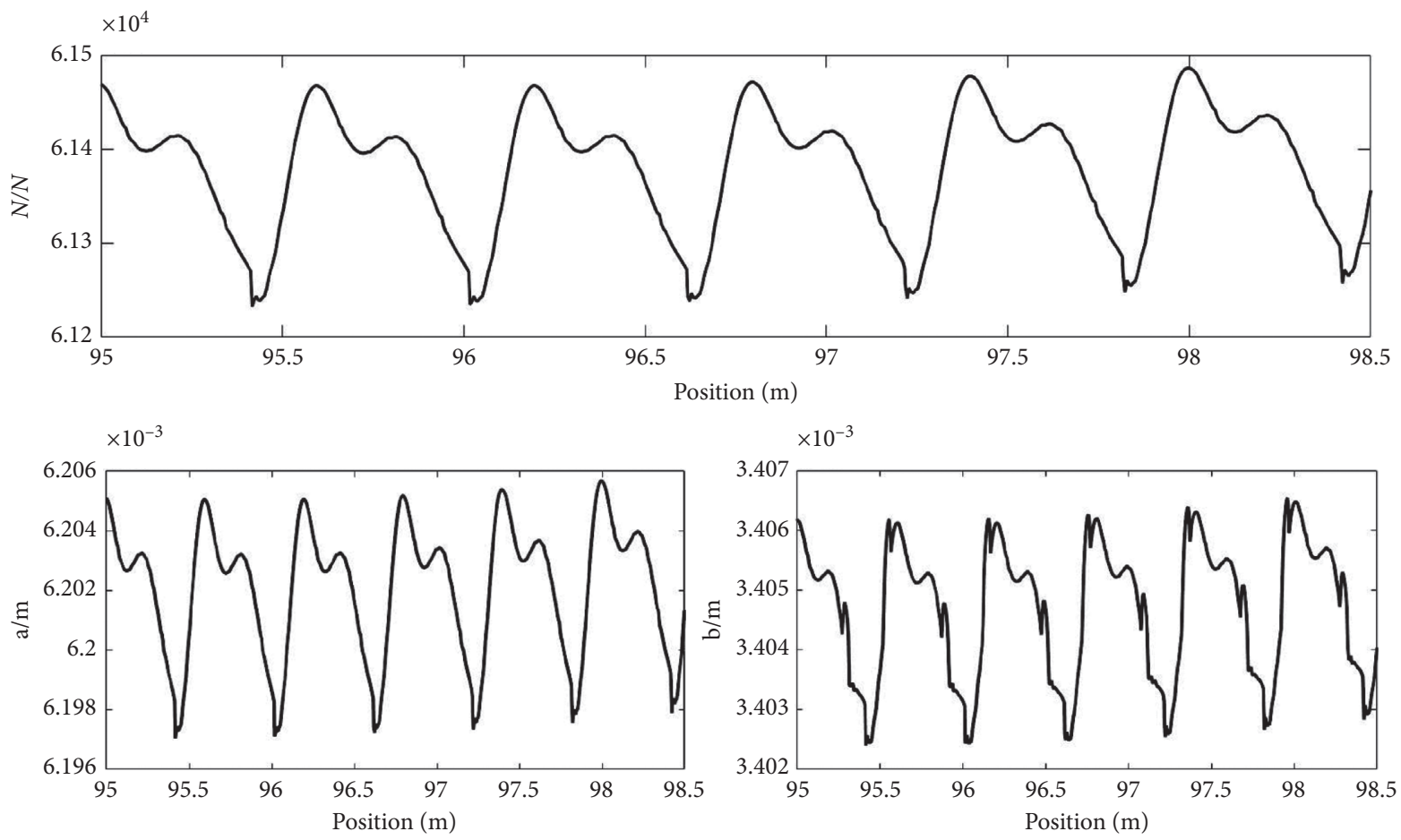

(a)
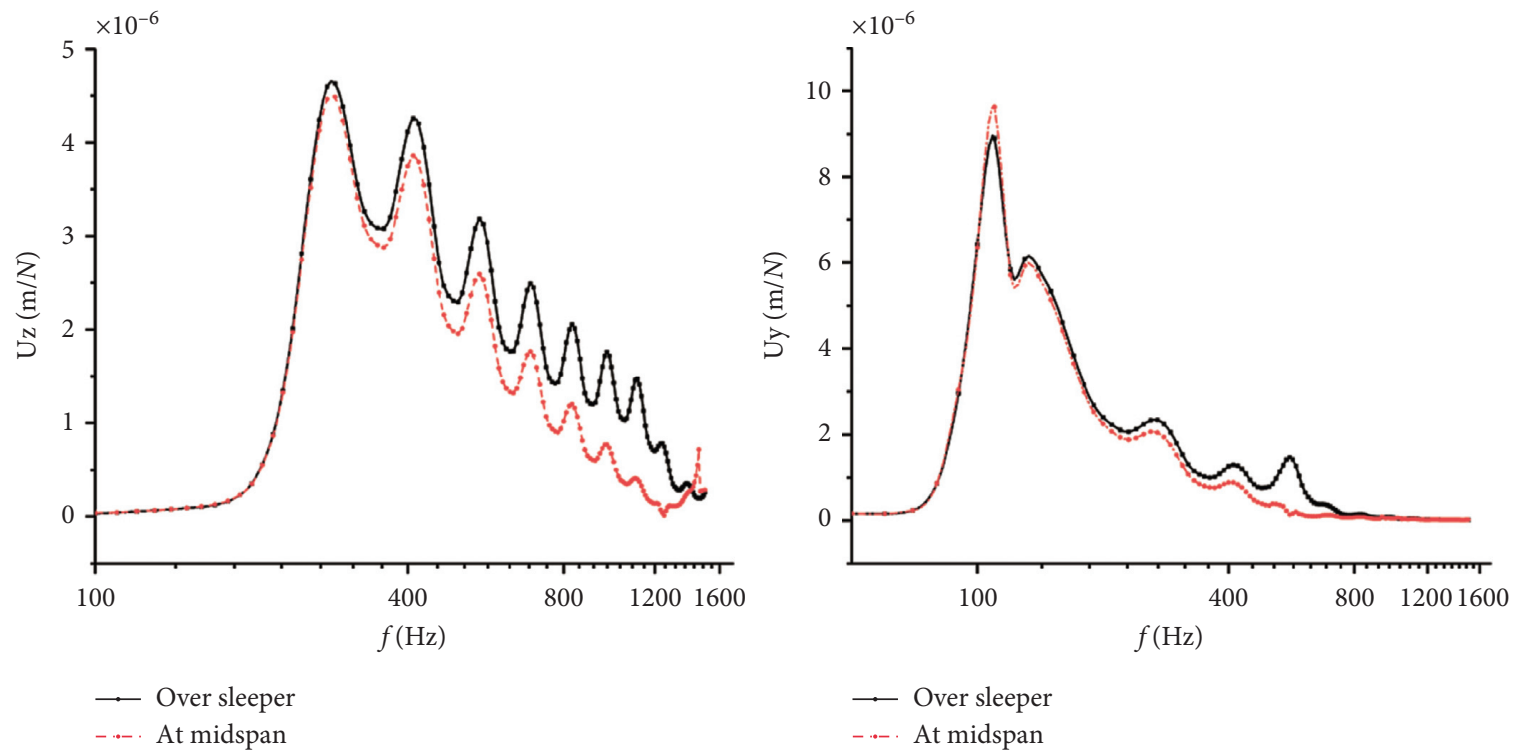

(b)

FIGURE 2: Fluctuation of related variables in the corrugation growth model: (a) influence of $x$ on model parameter; (b) influence of $x$ on rail receptance.

is larger than $40 \mathrm{MN} / \mathrm{m}$. In comparison with the other two factors, the sleeper spacing $d_{f}$ has less influence on the corrugation growth but the dominant frequency of corrugated wear as shown in Figure 3(c). As the excitation frequency $w_{f}$ varies inversely with $d_{f}$ to some extent, it obtains through analysis that along with the increase of $d_{f}$, the corrugation passing frequency and its growth rate decrease exponentially. However, the overall trend is gradually weakened when $d_{f}$ climbs to $0.65 \mathrm{~m}$.
Remark 3. In this section, the corrugation growth model is modified based on the wheel-rail dynamics. It proposes that the key factors influencing the rail corrugation growth are $R, d_{f}$, and $k_{z}$. With the help of sensitivity analysis, it can be concluded that $R$ and $k_{z}$ contribute the most to the corrugated wear rate while $k_{z}$ and $d_{f}$ have relatively more contribution on the corrugation passing frequency (as well as the wavelength of rail corrugation). The theoretical deduction shows that the excitation of vehicles passing by is 


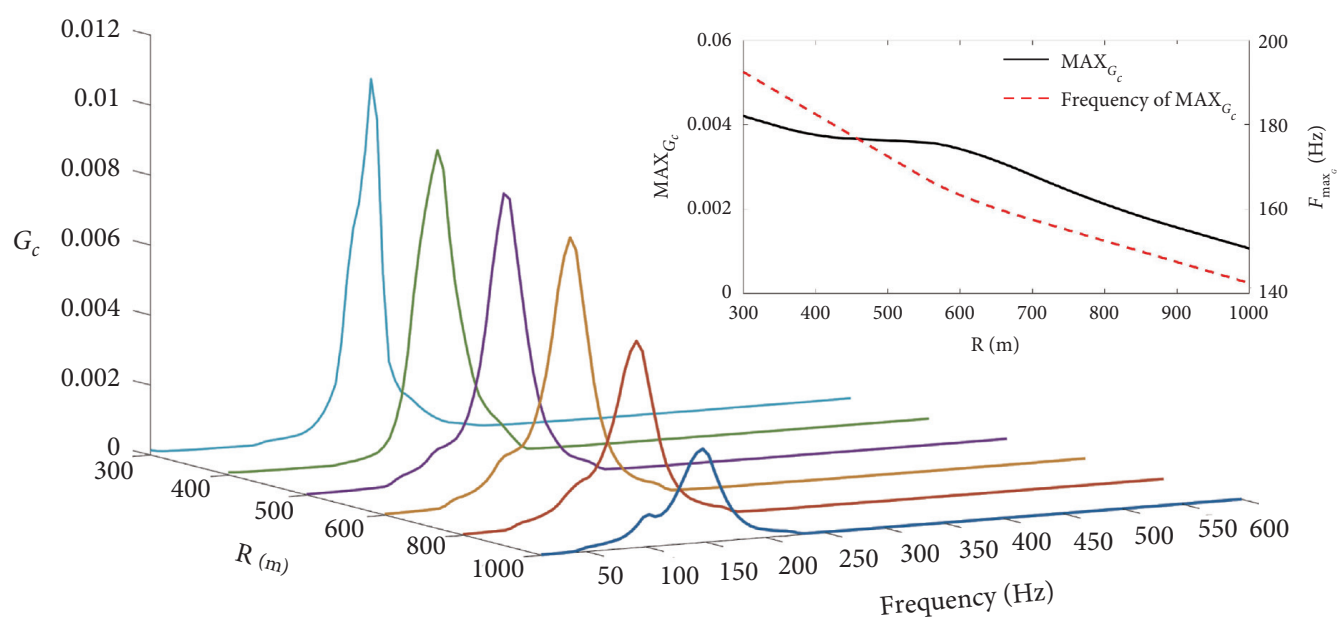

(a)

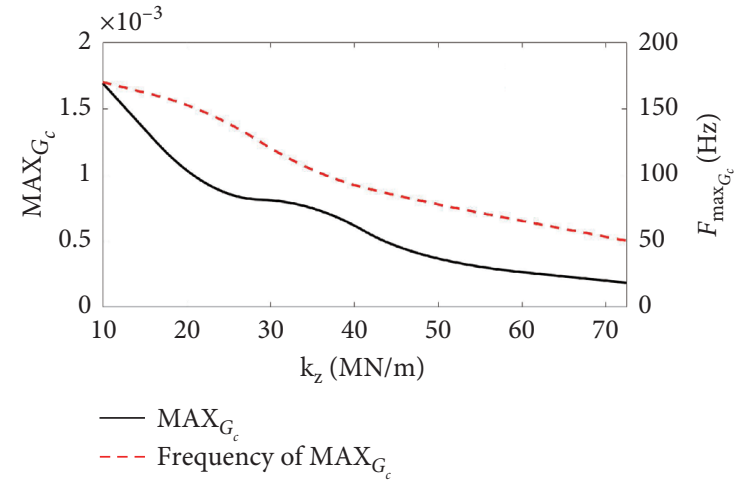

(b)

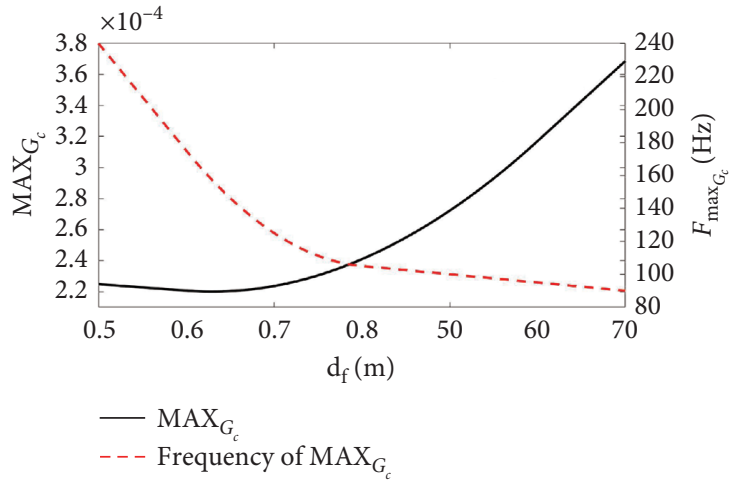

(c)

FIGURE 3: Sensitivity analysis results. (a) Effect of curve radius on corrugation growth. (b) Effect of support stiffness on corrugation growth. (c) Effect of sleeper spacing on corrugation growth.

indispensable for rail corrugation. In the following, the corrugation growth under different track conditions is calculated by using cosimulation, while the corrugation superposition model and simulation environment are introduced in the next subsection for corrugation evolution estimations and the validation of the calculated results of the corrugation growth from the aspect of material friction and wear.

3.2. Corrugation Superposition Model. This section establishes the corrugation superposition model in view of material friction and wear, where the position of the troughs, peaks, and the main corrugated wear wavelength can be observed. According to the friction work theory in the Archard wear model [61], the rail wear mass $\Delta m_{i}$ produced is proportional to the friction work, and the wear rate in the same section is consistent, while in fact, compared with the wave crest, the rail trough wear is more serious. To solve this problem, the possible contact area near the contact point is discretized in this paper, and the wear calculation is carried out in a sufficiently small section. In the simulation, the sampling interval is $0.00007 \mathrm{~s}$, the vehicle speed is calculated as $50 \mathrm{~km} / \mathrm{h}$, so the wear measurement point can be taken every $1 \mathrm{~mm}$. And it is reasonable for the calculation of the medium and shortwave corrugation studied in this article. Assuming that the friction power $P_{i}(x, n)$ remains constant in a short time step $\Delta t$, the wear depth $\mathrm{d}_{i}(x, n)$ can be expressed as

$$
\mathrm{d}_{i}(x, n)=\frac{\Delta m_{i}(x, n)}{A \rho}=\frac{k P_{i}(x, n)}{A \rho},
$$

where $A$ is the wheel-rail contact area at position $x$.

Add the wear depth and the original irregularity as the new rail irregularity to repeat the wear calculation, the accumulated wear $W(x, n)$ after $n$ trains passed is given as follows:

$$
W(x, n)=\mathrm{d}_{i}(x, n)+z_{r}(n-1),
$$

where $z_{r}(n-1)$ is the rail vertical irregularity after $(n-1)$ trains passed.

The material wear coefficient $k$ is the practical value of $2.103 \times 10^{13} \mathrm{~m}^{3} / \mathrm{J}$, and the material density $\rho$ of the $60 \mathrm{~kg} / \mathrm{m}$ rail used in China is $7800 \mathrm{~kg} / \mathrm{m}^{3}$. Alternatively, other unknown variables need to be determined by numerical simulation, including track receptance $\left(U_{z}, U_{y}\right)$ and wheelrail contact parameters $\left(N, a, b, P_{i}(x), A\right)$, etc. The simulation environment is stated in the next section. 


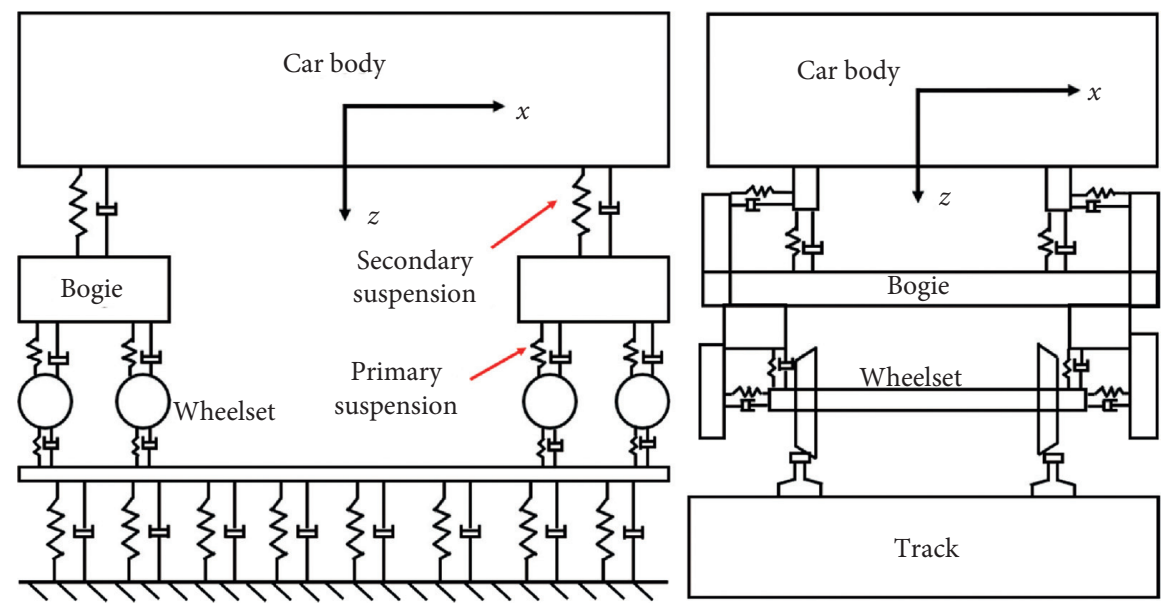

(a)

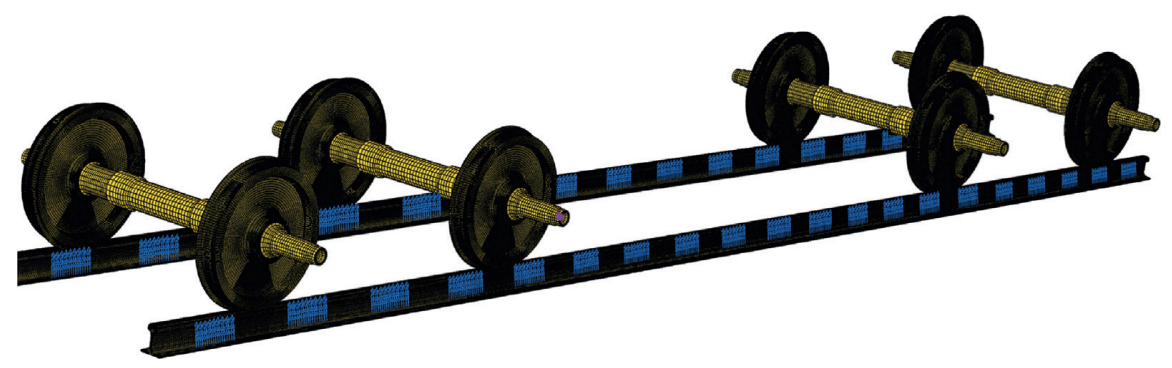

(b)

FIgURE 4: The finite element model of the wheel-rail system. (a) Discrete elastic supportive beam. (b) FEM of wheel-rail system.

3.3. Simulation Environment and Data Application. In this section, the finite element model (FEM) [62] of the wheel-rail system is built for rail receptance calculation and vibration modal analysis. The vehicle-track coupling dynamic model is established to obtain the wheel-rail contact parameters for $G_{c}$ as well as the friction work variables for rail wear. The midpoint of circular curve is taken as the testing point.

This paper aims at the common short sleeper track structure, whose short sleepers are embedded in the track slab and consolidated together with no damping between them. The track bed has little effect on the high-frequency vibration $(>50 \mathrm{~Hz}$ ) induced by the shortwave grinding of the subway [63]. To facilitate modelling, the short sleeper is not considered separately and the lower structure is considered as a whole. The rail support stiffness and damping in the model are only the stiffness and damping of the fastener, so a relatively simple single-layer elastic point-support beam model can be used for analysis as shown in Figure 4(a). In this model, the load of the entire vehicle is evenly distributed among the four wheelsets. Furthermore, the FEM simplifies the loading method and boundary constraints to facilitate analysis. The load added at both ends of the wheelset is applied to the axle journals at both ends of the axle through distributed coupling, and the lateral and vertical forces acting on the track are balanced by the track support force. The boundary constraints of wheelset are applied to the center of both ends of the axle, and the hinged-hinged constraints are added to the two ends of the rail. The track in FEM is long enough to ignore tail effects. The elastic fasteners and gaskets between the rail bottom and the foundation are simulated by nondimensional springs and damping elements. This model uses C3D8I hexahedral elements in ANSYS to divide the mesh, with a total of 578,752 nodes and 498,648 elements. The actual support structure under rail is modelled by changing the stiffness and damping of the spring as shown in Figure 4(b).

The vehicle-track coupling dynamics model is built by using the dynamic software Universal Mechanism (UM) [64], where the B-type vehicle structure used by Guangzhou Metro is used as the modelling prototype. In this model, the Euler beam is adopted as the rail model, and the total length of the flexible track structure is $500 \mathrm{~m}$. The track irregularity in this model is the measured irregularities of Guangzhou Metro Line 3, where no initial corrugation is found. In dynamic calculations, the KIK-Piotrowski contact model is used to simulate the normal parameters of wheel-rail contact [65]. The FASTSIM algorithm is used to calculate the tangent contact parameters of the wheel-rail contact system.

The friction power $P_{i}(x)$ and the contact area $A$ can be directly obtained by vehicle dynamics simulation. The corrugated wear in the time domain can be calculated directly by substituting them into equation (35), from which one can observe the corrugated wear depth. By using the MATLAB toolbox, the power spectrum corresponding to the one-third octave band is calculated, where the evolution tendency of the corrugation grade (CG) with the cumulative number of vehicles passing by (CVP) and the passing frequency can be extracted. 


\section{Causation Analysis of Rail Corrugation}

This section calculates the corrugation growth based on the cosimulation, and the relation between the corrugation passing frequency and the track natural vibration frequency is discussed.

\subsection{The Corrugation Growth under Various Track Parameters.} With the help of ANSYS, the rail receptance $\left(U_{y}, U_{z}\right)$ is calculated for different track parameters. Due to space limitations, only the receptance of curved-track with different radii is shown in Figure 5.

There is a peak response for both $U_{y}$ and $U_{z}$ for different track radii. The track with a small radius has a much smaller response, and the corresponding frequency of the peak is larger. Additionally, with the increase in the support stiffness, the vertical and lateral track receptance tend to decrease. Meanwhile, the corresponding frequencies move toward lower. Furthermore, the impact of the support spacing on the natural vibration cannot be ignored, especially for vibrations in the frequency range of $10 \mathrm{~Hz}-400 \mathrm{~Hz}$. Dense sleepers lead to high-frequency short wave vibration with small amplitude, while large support spacing aggravates the low-frequency vibration of the track. The calculated results are in good agreement with those conclusions in $[47,66]$.

The corrugation growth function is obtained as shown in Figure 6. It shows that the rail corrugation growth on a curved track with smaller radii achieves a larger value, which means that corrugation is more likely to occur on a small radius curve, and it is consistent with the frequent locations of the rail corrugation on-site. In fact, the maximum value of the corrugation growth $G_{c}$ for a track with a radius of $200 \mathrm{~m}$ is $3.83 \times 10^{-3}$, while the value for a track with a radius of $1000 \mathrm{~m}$ is $0.87 \times 10^{-6}$, which is much smaller. The primary frequency of the corrugation on the curved track with a radius of $200 \mathrm{~m}$ is $202 \mathrm{~Hz}$. The primary frequency of the curved rail with radii of $300 \mathrm{~m}, 400 \mathrm{~m}$, and $1000 \mathrm{~m}$ is $184 \mathrm{~Hz}$, $168 \mathrm{~Hz}$, and $78 \mathrm{~Hz}$, respectively. As the running speed of the train is $50 \mathrm{~km} / \mathrm{h}$, the wavelengths of rail corrugation in the above four curves are obtained as follows:

$$
\begin{aligned}
& \lambda_{R 200}=\frac{v}{f_{R 200}}=69 \mathrm{~mm}, \\
& \lambda_{R 300}=\frac{v}{f_{R 300}}=75 \mathrm{~mm}, \\
& \lambda_{R 400}=\frac{v}{f_{R 400}}=83 \mathrm{~mm}, \\
& \lambda_{R 1000}=\frac{v}{f_{R 1000}}=178 \mathrm{~mm} .
\end{aligned}
$$

The corrugation growth rate $G_{c}$ variation to the support stiffness is shown in Figure 6(b). It shows that the track with a smaller support stiffness is more likely to form corrugation with a lower frequency and a longer wavelength, which verifies the conclusion in [47]. For the curved track with a support stiffness of $k_{z 1}$, the primary frequency is $172 \mathrm{~Hz}$, and the wavelength is $80 \mathrm{~mm}$. When the support stiffness of the track increases to $k_{z 4}$, the passing frequency is approximately $80 \mathrm{~Hz}$, and the corrugation wavelength is only $173 \mathrm{~mm}$.

Figure 6(c) shows that reducing the sleeper spacing effectively suppresses the corrugated wear. More importantly, the sleeper spacing seriously affects the corrugation wavelength. The figure shows that for a track structure with a support spacing of $0.5 \mathrm{~m}$, the corrugation frequency is $202 \mathrm{~Hz}$. When the sleeper spacing increases to $0.8 \mathrm{~m}$, the primary frequency of corrugation decreases to $150 \mathrm{~Hz}$. The above results are consistent with the sensitivity analysis of the previous corrugation growth $G_{c}$ and also consistent with the experimental results in [66].

4.2. The Relation between Corrugation Passing Frequency and Track Natural Vibration Frequency. To investigate the track vibration related to rail corrugation, the modal analysis of the curved track is carried out. Taking the modal analysis of curved tracks with different radius as an example due to space limitations, Figure 7 shows the typical vibration modal of the curved track. At $196 \mathrm{~Hz}$, the fifth-order vertical bending vibration coupled with transverse torsional vibration occurs. As the natural frequency of $196 \mathrm{~Hz}$ is close to the resonance frequency $(202 \mathrm{~Hz})$ of the corrugation growth function $G_{c}$ in Figure 6(a), it reveals that the corrugation is directly related to this fifth-order vertical bending vibration.

Similarly, the 4th-order bending torsional vibration of $190 \mathrm{~Hz}$ in the curved track with a radius of $300 \mathrm{~m}$ results in corrugation with a wavelength of $75 \mathrm{~mm}$. The vertical 4 thorder bending vibration of $148 \mathrm{~Hz}$ in the curved track with a $400 \mathrm{~m}$ radius determines rail corrugation with the main wavelength of $94 \mathrm{~mm}$. The long corrugation (wavelength $178 \mathrm{~mm}$ ) on the inner rail of a $1000 \mathrm{~m}$ radius curve is caused by the first-order lateral bending vibration of the curved track at $82 \mathrm{~Hz}$.

Therefore, how is the natural vibration of the track excited? It is certainly excited by the passing vehicles. For a curved track with sleeper spacing of $0.6 \mathrm{~m}$, the excitation frequency caused by a vehicle passing at a speed of $50 \mathrm{~km} / \mathrm{h}$ is $23 \mathrm{~Hz} f=\left(v / \mathrm{d}_{f}\right)$. The natural frequency of the track related to corrugation is close to a certain frequency doubling of the vehicle passing excitation. For example, the natural frequencies of the above four curved tracks with different radii are $196 \mathrm{~Hz}, 190 \mathrm{~Hz}, 148 \mathrm{~Hz}$, and $82 \mathrm{~Hz}$, which are approximately nine times, eight times, six times, and four times the driving frequency, respectively.

For railway tracks with different sleeper spacings, the excitation frequency due to the vehicle passing by is calculated as shown in Table 2. The results show that the primary frequency of rail corrugation in the curves with different sleeper spacings is quite different. However, it is very close to the natural vibration frequency of the track and a high-order harmonic frequency of the excitation frequency.

Remark 4. The higher harmonic resonances of the track are excited when the vehicle passes by due to its discontinuous support characteristics, and it causes the initial corrugated 


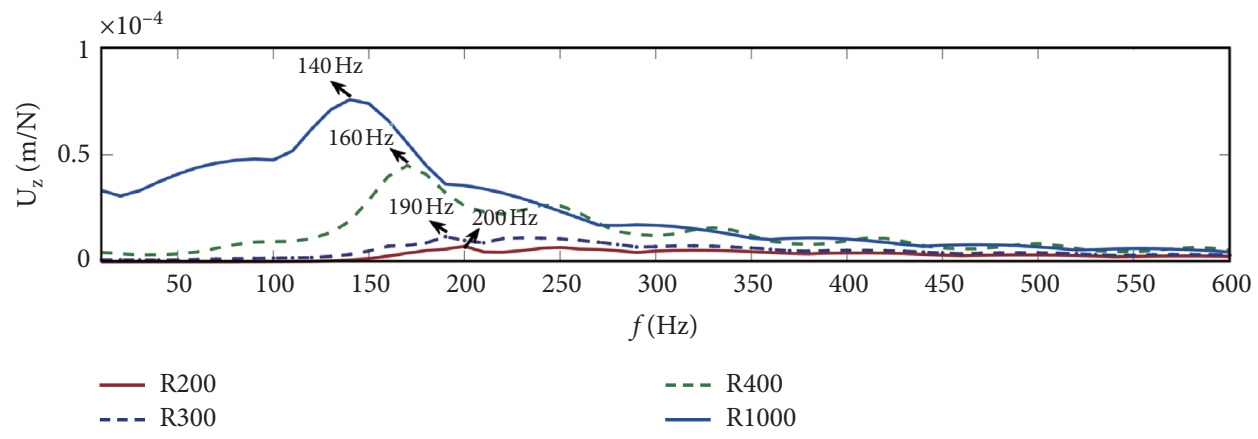

(a)

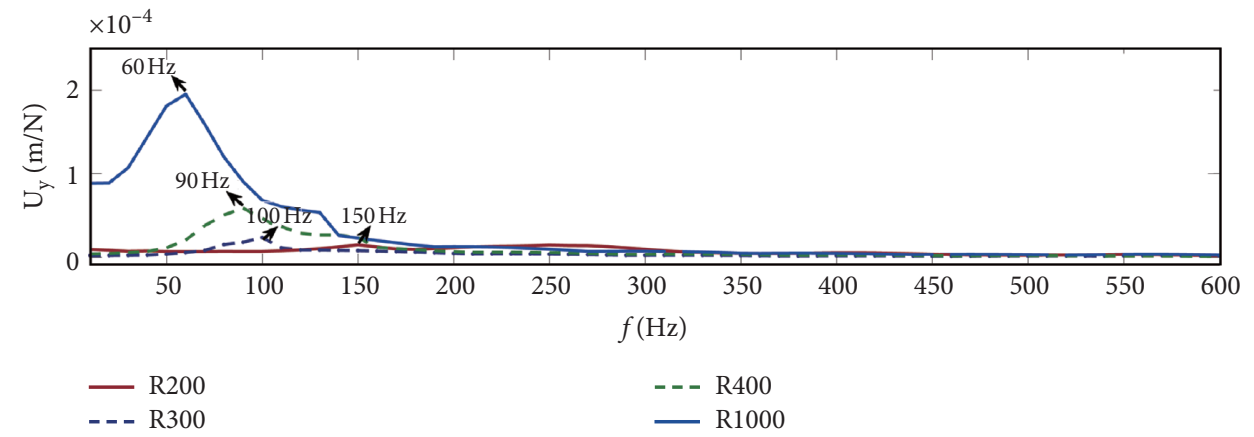

(b)

Figure 5: Receptance of the inner rail for different track radii $(a, b)$.

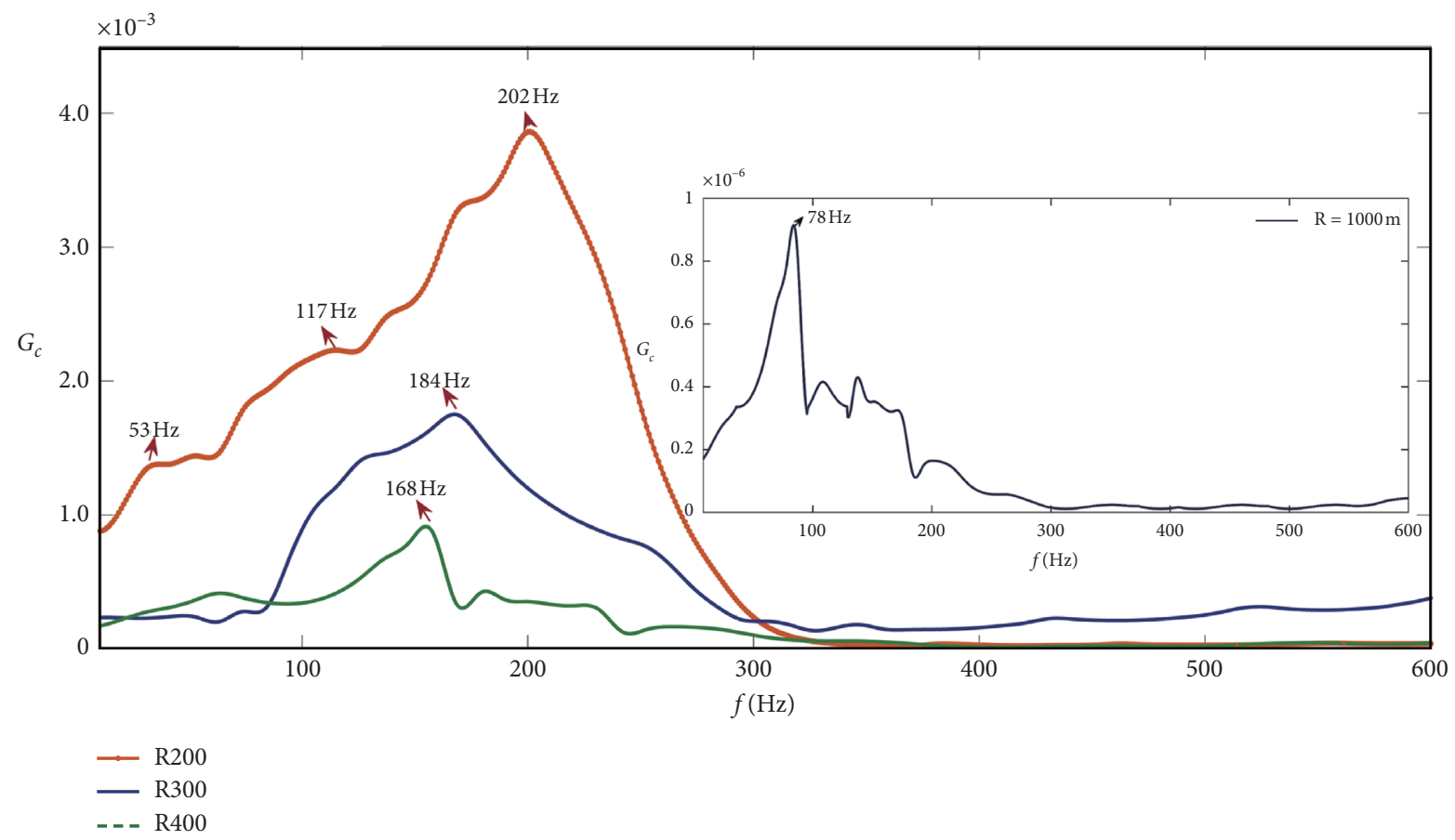

(a)

Figure 6: Continued. 


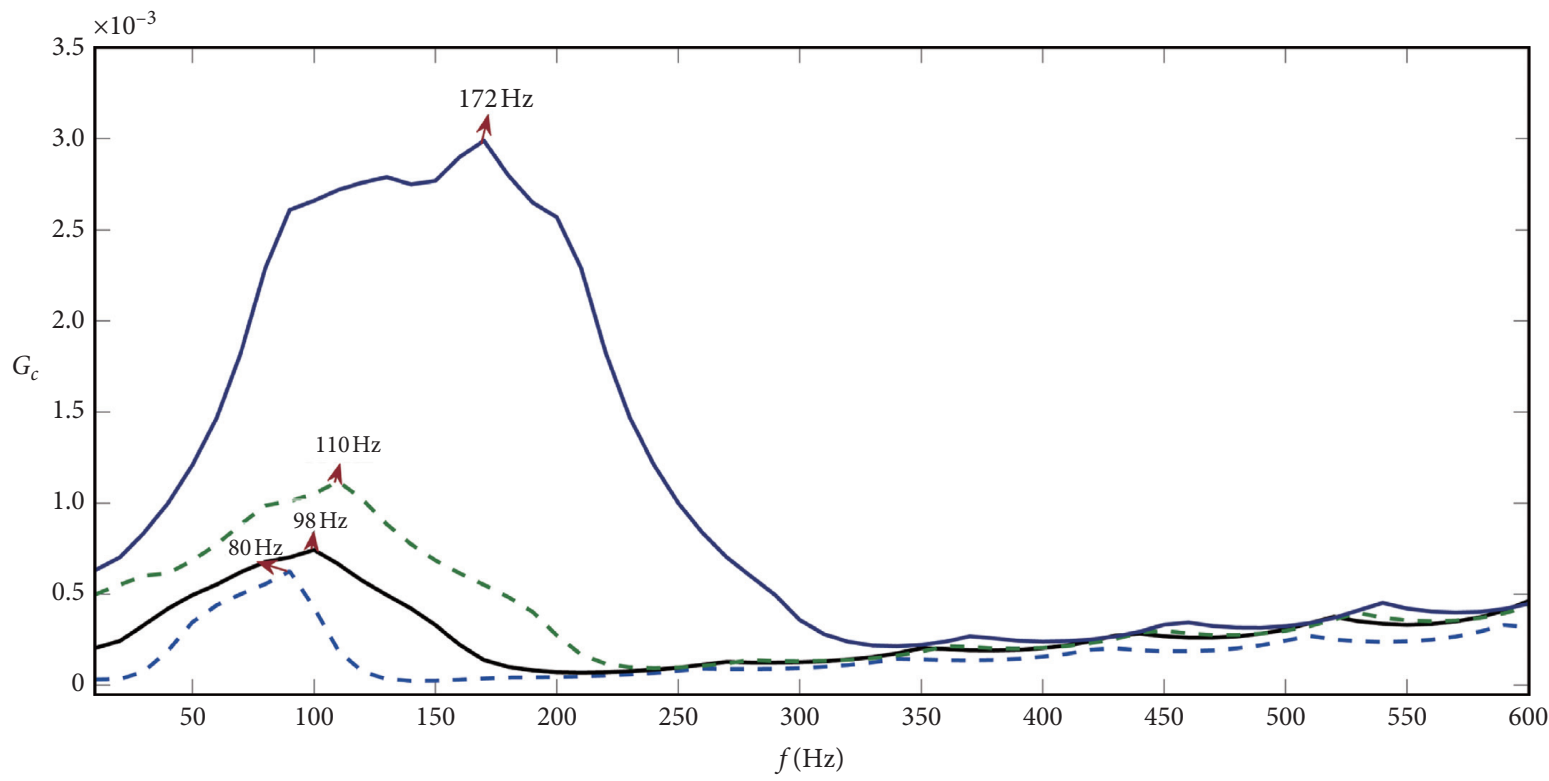

$$
\begin{aligned}
&-\mathrm{k}_{\mathrm{z} 1}=10 \mathrm{MN} / \mathrm{m} \\
&---\mathrm{k}_{\mathrm{z} 2}=20 \mathrm{MN} / \mathrm{m}-\mathrm{k}_{\mathrm{z} 3}=30 \mathrm{MN} / \mathrm{m} \\
&---\mathrm{k}_{\mathrm{z} 4}=70 \mathrm{MN} / \mathrm{m}
\end{aligned}
$$

(b)
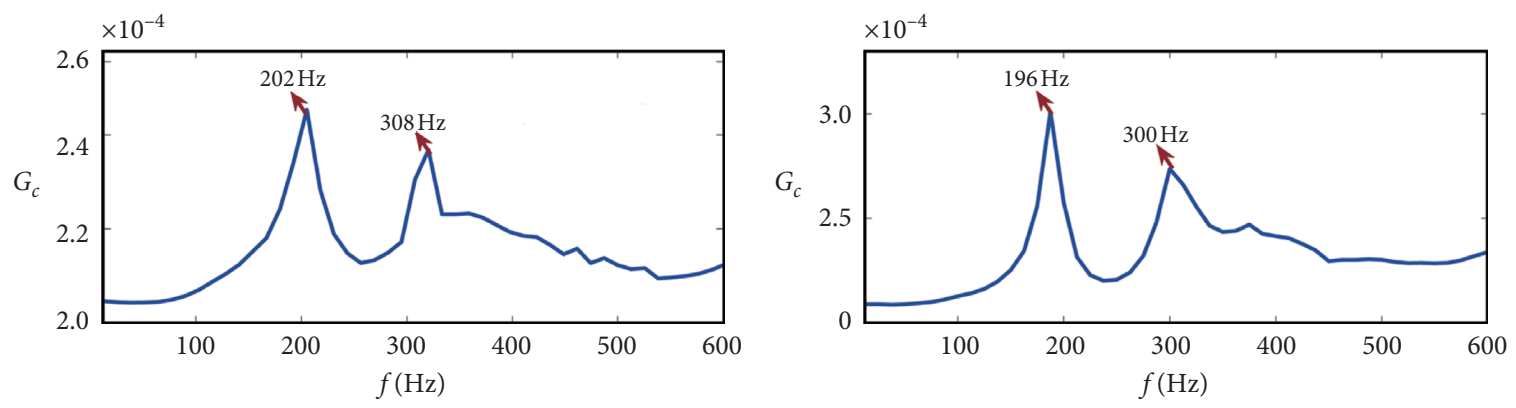

$\mathrm{d}_{f 1}=0.5 \mathrm{~m}$
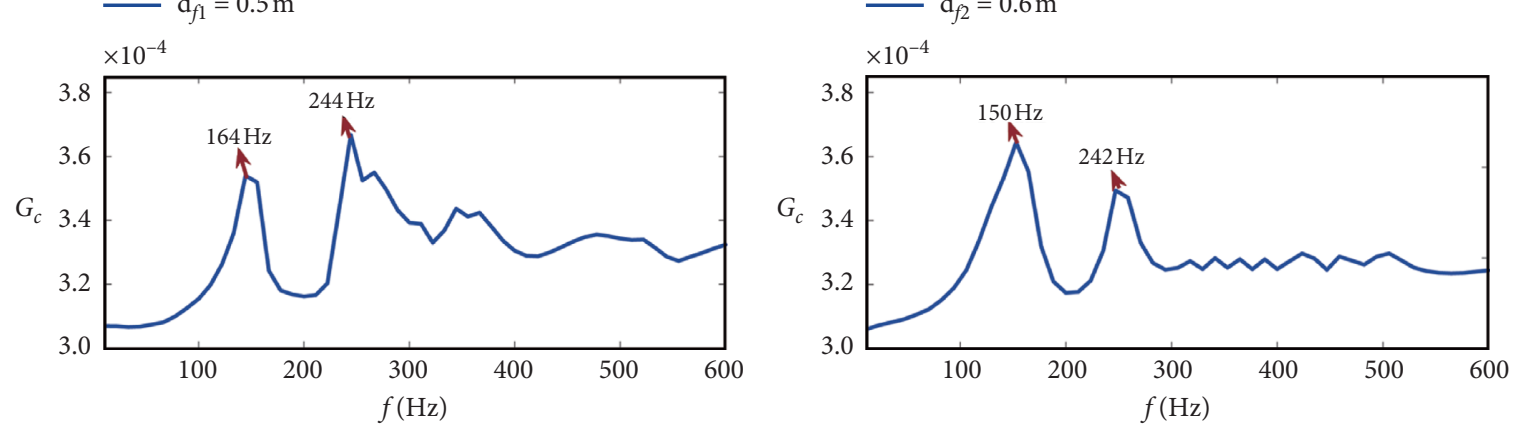

$\mathrm{d}_{f 3}=0.7 \mathrm{~m}$

$\mathrm{d}_{f 4}=0.8 \mathrm{~m}$

(c)

FIGURE 6: Growth curve of the corrugation on different curved tracks. (a) Corrugation growth curve of curved rail with different radius. (b) Corrugation growth curve of curved rail with different support stiffness. (c) Corrugation growth curve of curved rail with different sleeping spacing. 


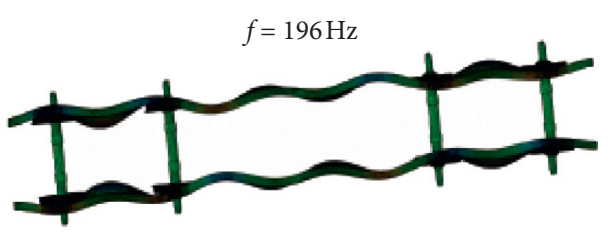

(a)

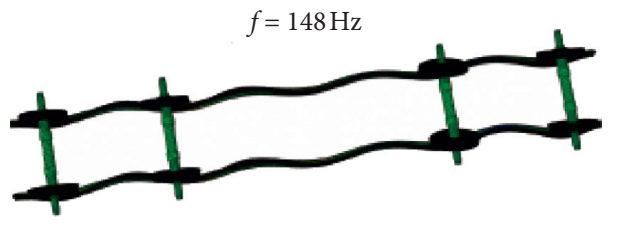

(c)

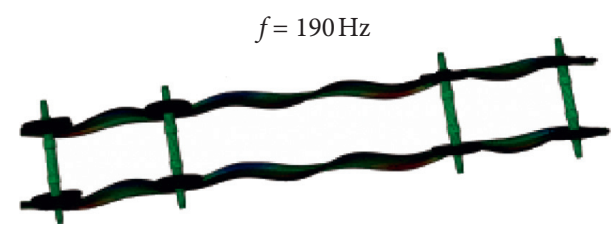

(b)

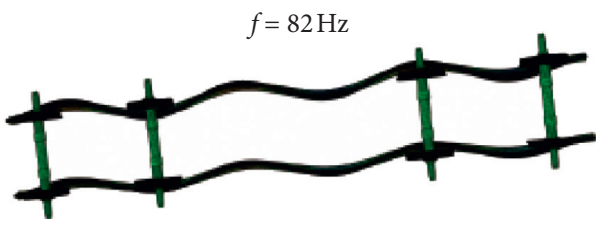

(d)

Figure 7: Natural vibration modal analysis of the wheel-rail system. (a) Typical modes of curved track with 200 m radius. (b) Typical modes of curved track with $300 \mathrm{~m}$ radius. (c) Typical modes of curved track with $400 \mathrm{~m}$ radius. (d) Typical modes of curved track with $1000 \mathrm{~m}$ radius.

TABLE 2: Frequency domain characteristics of corrugation of different curves.

\begin{tabular}{lcccc}
\hline $\begin{array}{l}\text { Support spacing of } \\
\text { curves } / \mathrm{m}\end{array}$ & $\begin{array}{c}\text { Vehicle passing } \\
\text { excitation/Hz }\end{array}$ & $\begin{array}{c}\text { Certain double } \\
\text { frequency/Hz }\end{array}$ & $\begin{array}{c}\text { Track natural } \\
\text { frequency/Hz }\end{array}$ & $\begin{array}{c}\text { Main frequency of } \\
\text { corrugation/Hz }\end{array}$ \\
\hline 0.5 & 28 & 196 & 200 & 208 \\
0.6 & 24 & 192 & 190 & 200 \\
0.7 & 20 & 160 & 172 & 172 \\
0.8 & 17 & 170 & 168 & 168 \\
\hline
\end{tabular}

wear on the rail surface. These results are completely different from the existing self-excitation theory and the otherexcited theory. And a new corrugation formation theory is innovatively presented. It is the vehicle passing speed and the discontinuity of track structure that directly excite the superharmonic resonance of the track structure, which eventually leads to rail corrugation. The wavelength of the corrugation depends on the high-order harmonic resonance frequency and the vehicle passing speed.

\section{Simulation of the Corrugation Evolution on a Curved Track Surface}

In this section, the accumulated rail wear under different scenarios is calculated. The results are found to be in good agreement with the calculation results of corrugation growth. However, due to space limitations, this section only introduces the results of the superimposed wear on a curved inner rail with different radii for validation by simulation.

Figure 8(a) shows the rail accumulated wear after 10 thousand vehicles pass by, where the curved rail with a small radius has a large wear on the surface. For example, the wear depth of the curved rail with a radius of $200 \mathrm{~m}$ is as deep as $0.117 \mathrm{~mm}$, while that of the curve with a radius of $1000 \mathrm{~m}$ is only $0.00632 \mathrm{~mm}$. That is, the corrugation on the small radius curve evolves much faster than that on curves with larger radii, which is consistent with the theoretical results of the previous sensitivity analysis.

Figure 8 (b) shows the $1 / 3$ octave frequency spectra of the rail wear, where the three primary wavelengths of the corrugation for the curved rail with a radius of $200 \mathrm{~m}$ are
$71 \mathrm{~mm}, 138 \mathrm{~mm}$, and $207 \mathrm{~mm}$. The corresponding passing frequencies are $196 \mathrm{~Hz}, 100 \mathrm{~Hz}$, and $67 \mathrm{~Hz}$. The primary wavelength of $71 \mathrm{~mm}$ is close to the calculation results $\lambda_{R 200}=69 \mathrm{~mm}$ of the corrugation growth model, as shown in Figure 6(a). Similar observations can be found for the other three rails.

As we calculated, with the decrease in the support stiffness of the track, the rail wear grows faster, and the shortwave wear becomes more prominent. Besides that, rail wear in different curves presents two characteristic frequencies. The larger frequency is the primary frequency of the corrugation, which decreases faster with the increase in the support stiffness. Furthermore, different sleeper spacing results in different wavelengths of corrugation, and shortwave wear expands faster on the tracks with dense supports. With the increase in sleeper spacing, the corrugation wavelength gradually increases. Similarly, the above wear frequencies are very close to the frequencies calculated in Figure 6(b) and 6(c).

To investigate the evolution of the wavelength and corrugation grade as the CVP steadily increases, the development trend of the CG at the primary passing frequency in different curves is calculated. And only the corrugation evolution with different radii is shown in Figure 9 due to space limitations.

It shows that the CG increases almost linearly with the increase of the CVP, where corrugation on a smaller curve develops faster. After a total of 20,000 trains pass by the track line, the corrugation level at the main frequency of $100 \mathrm{~Hz}$ is $-42 \mathrm{~dB}$ for the curve with a radius of $200 \mathrm{~m}$. It is only $-62 \mathrm{~dB}$ in the curve with a radius of $1000 \mathrm{~m}$. When the total traffic 

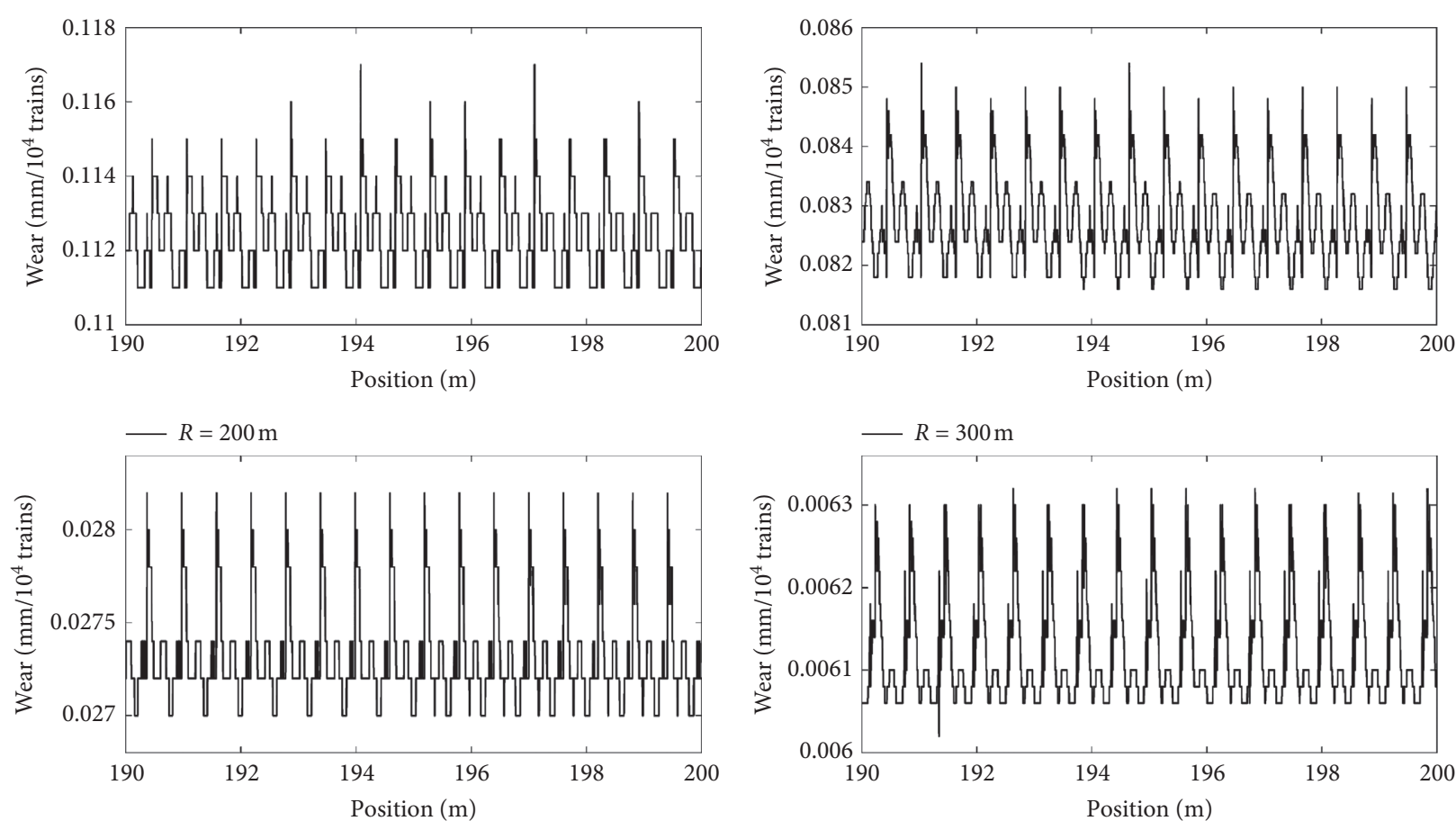

$R=400 \mathrm{~m}$

$-R=1000 \mathrm{~m}$

(a)
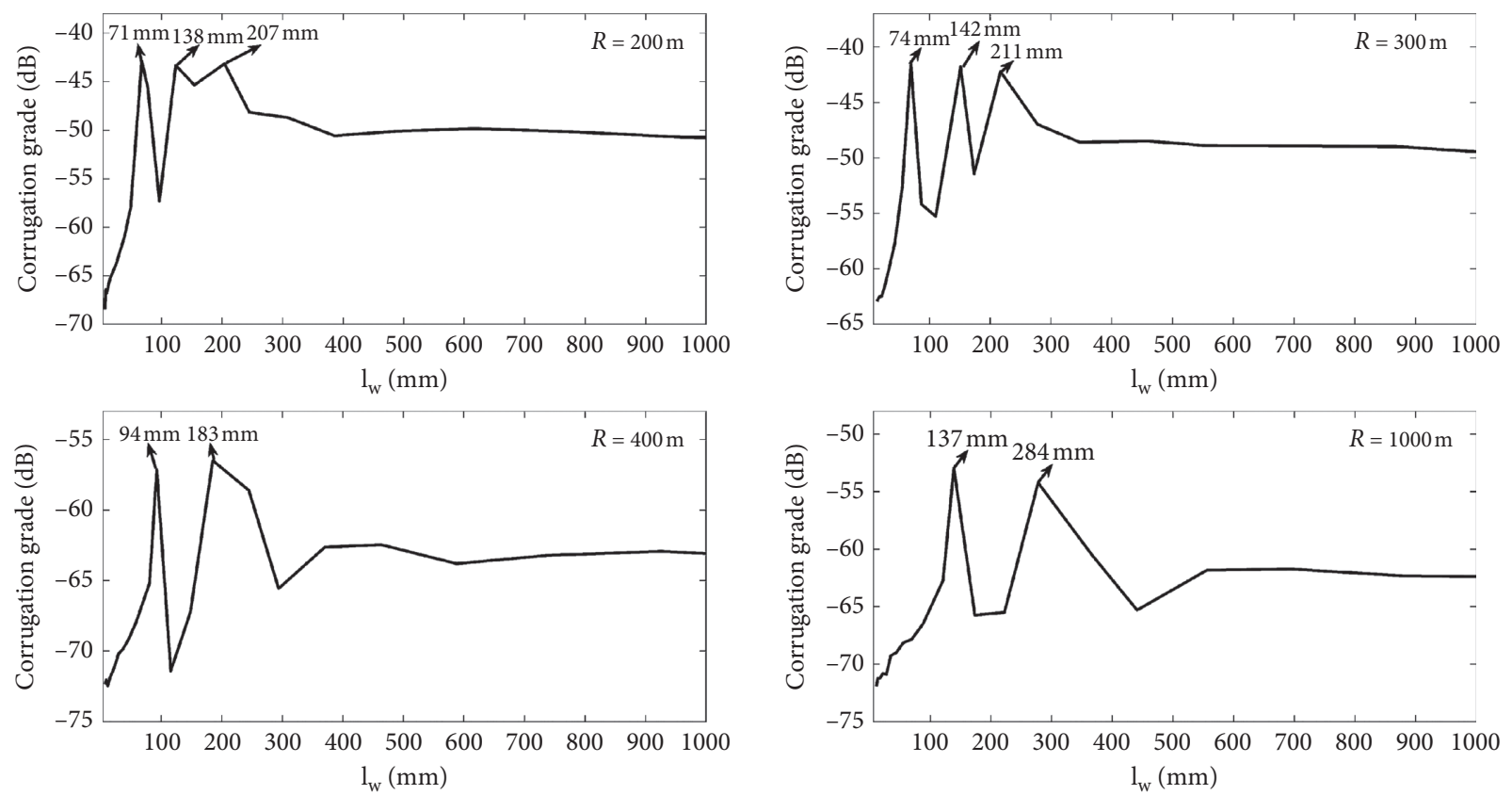

(b)

FIGURE 8: Time-frequency analysis curve of rail wear in curves with different radii. (a) Rail wear of curved track with different radius. (b) One-third octave spectrum curve of rail wear.

volume reaches 80,000 trains, the corrugation grade increases to $-32 \mathrm{~dB}$, an increase of $10 \mathrm{~dB}$. With the same traffic volume, the corrugation grade at the same frequency on the radius of $1000 \mathrm{~m}$ only increases to $-56 \mathrm{~dB}$, with an increase of $6 \mathrm{~dB}$.
The CG on the curves with different support stiffness and sleeper spacing is calculated, respectively. The results show that the passing frequency of the corrugation is not affected by the CVP on the track line. For a curved track, the growth rate of shortwave corrugation is higher than that of longwave 

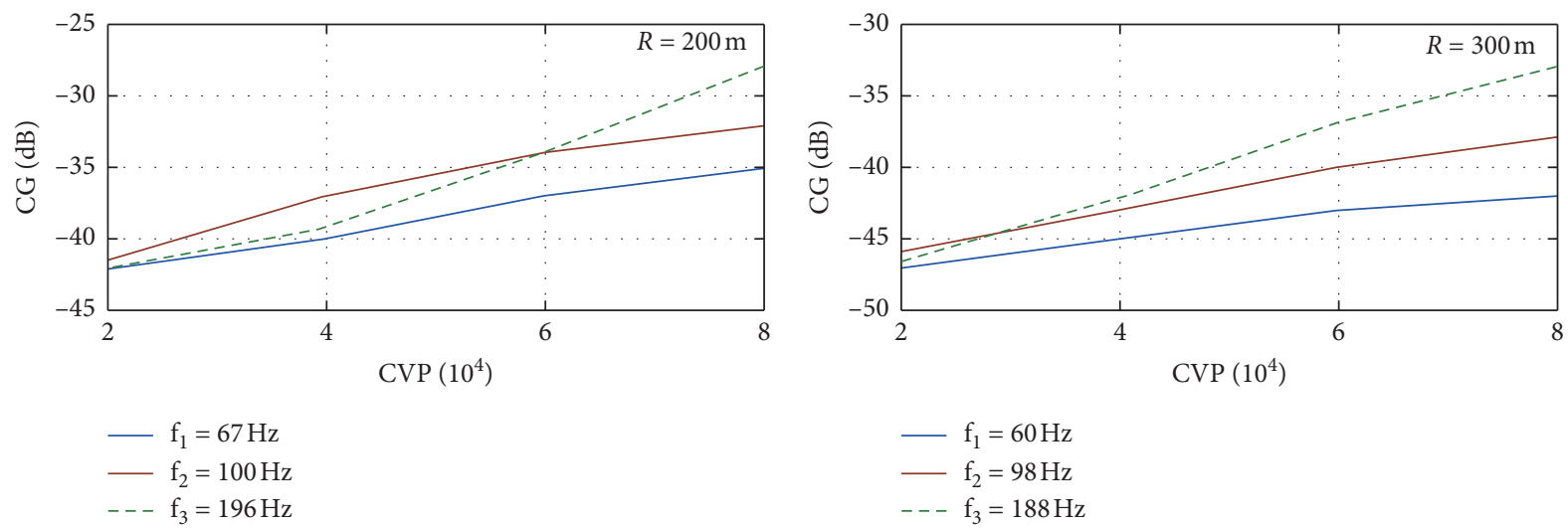

(a)

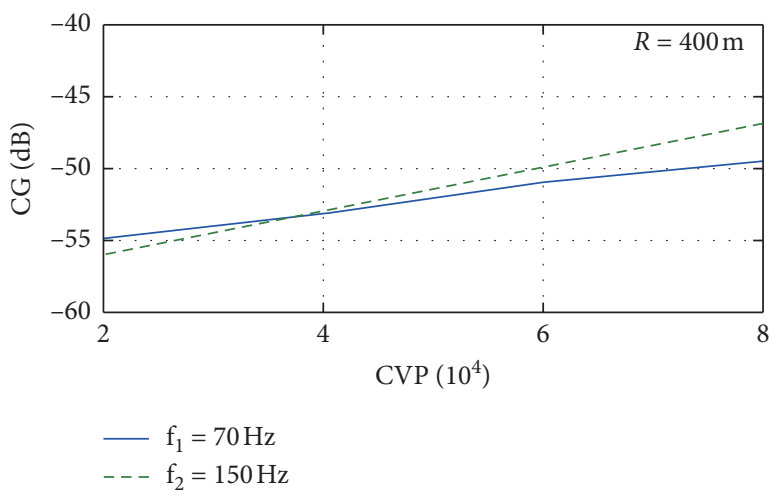

(c)

(b)

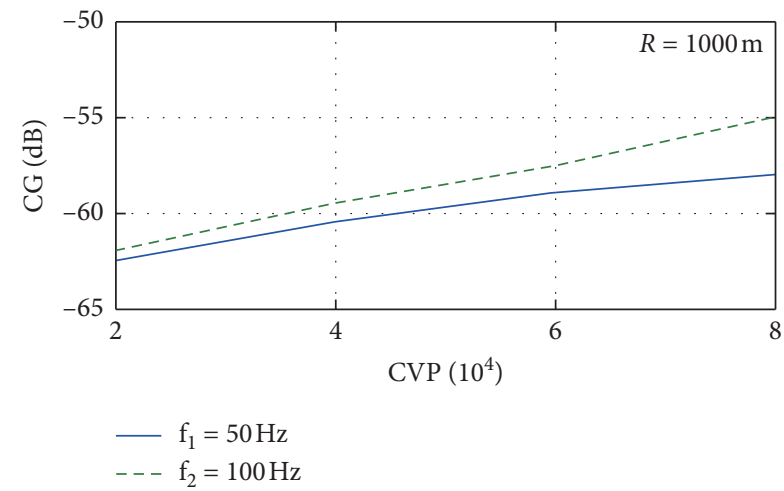

(d)

FIGURE 9: Comparison of corrugation grades on curved tracks with different radii (a), (b), (c), and (d).

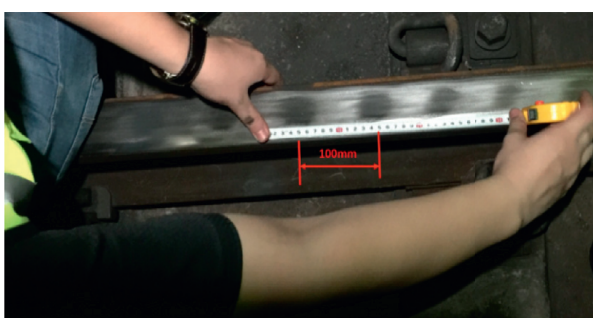

(a)

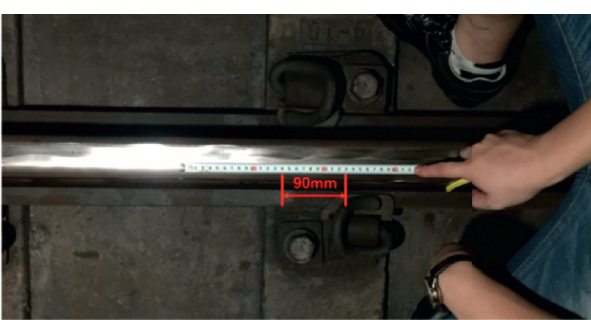

(b)

FIgURE 10: The typical corrugation of the downward curve of Shi-Pan Station. (a), (b).

corrugation, and its development is accelerated by the decrease in support stiffness. Moreover, different sleeper spacings have little impact on the development of that. Therefore, the adjustment of the support stiffness or sleeper spacing affects the corrugation wavelength, and the development of corrugations is significantly affected by the support stiffness. In the next section, the corrugation measured from Guangzhou Metro is introduced to verify these studies.

\section{Validation of the Rail Corrugation Causation and Evolution with Field Measurements}

According to the quarterly monitoring data on-site, the internal track of the downward line from Shiqiao Station to Panyu Square Station of Guangzhou Metro Line 3 is a section with frequent corrugation. The measured track section selected in this paper is common short sleeper with monolithic track bed, and the curve radius is $300 \mathrm{~m}$ with the 


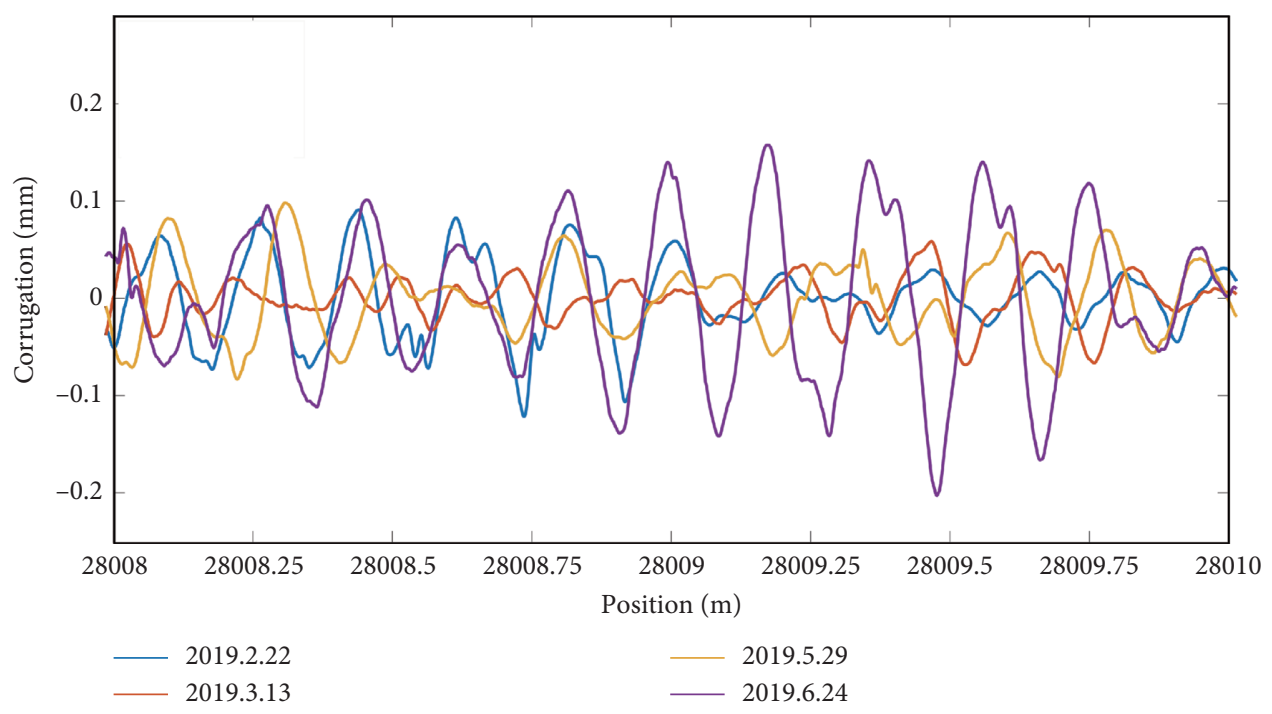

(a)

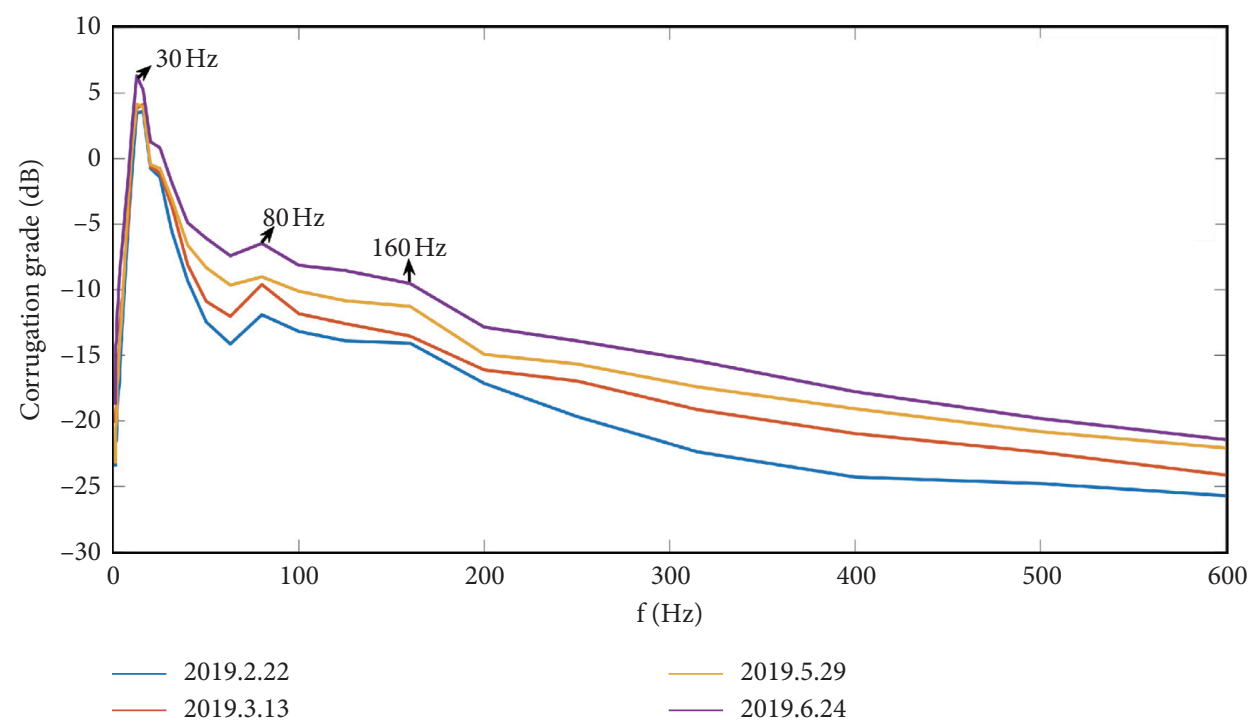

(b)

FIGURE 11: Time-frequency analysis curve of measured corrugation in Shi-Pan down track section. (a) Measurement of local rail wear. (b) One-third octave spectrum curve of measured rail wear.

superelevation of $100 \mathrm{~mm}$. The medium and long waves are dominant, as shown in Figure 10.

Figure 11(a) shows the measured rail corrugation obtained from four on-site tests with the help of the CAT corrugation inspection vehicle. During these four tests, no grinding treatment is carried out. The corrugation grows gradually with the increase of the CVP. The maximum corrugation depth evolves from $0.084 \mathrm{~mm}$ at the first inspection to $0.157 \mathrm{~mm}$ at the fourth inspection. The periodicity of the corrugation becomes increasingly significant from the first inspection to the fourth.

Figure 11(b) shows the frequency spectrum of the rail corrugation within $600 \mathrm{~Hz}$, where the primary and secondary frequency is $80 \mathrm{~Hz}$ and $160 \mathrm{~Hz}$, separately. With the increase in CVP, these two frequencies of the corrugation hardly change. The running speed of vehicles in this section is approximately $60 \mathrm{~km} / \mathrm{h}$, and the corresponding wavelengths of the corrugation are calculated as $208 \mathrm{~mm}$ and $104 \mathrm{~mm}$. The shortwave corrugation develops more rapidly with the increase in CVP. This is in good agreement with the previous simulation results.

The vibrating modal analysis of the measured track structure is shown in Figure 12. The track structure is dominated by vertical second-order bending vibration with slight torsional vibration at $75 \mathrm{~Hz}$, and the coupling of vertical high-order bending and severe torsion is observed at $160 \mathrm{~Hz}$. The frequencies coincide with the corrugation dominant frequencies, which verifies the conclusion obtained from the above simulation that the generation of rail corrugation is related to the natural mode of the track.

How are these two natural modes excited? The sleeper spacing is $0.625 \mathrm{~m}$, and the vehicle passing frequency is 


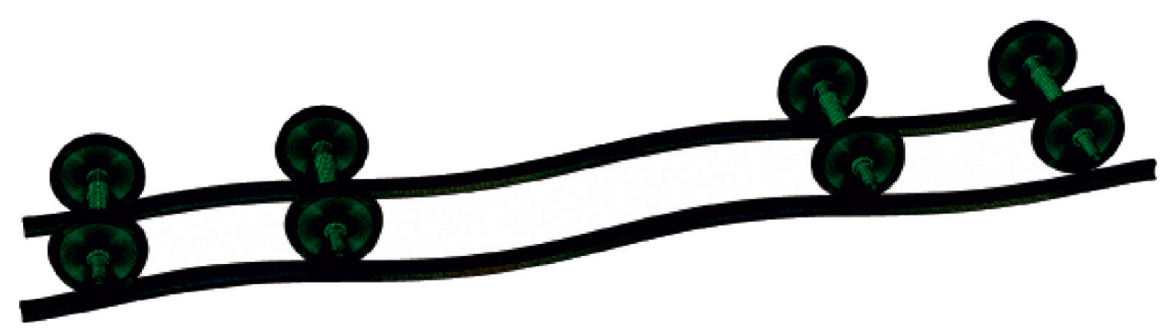

(a)

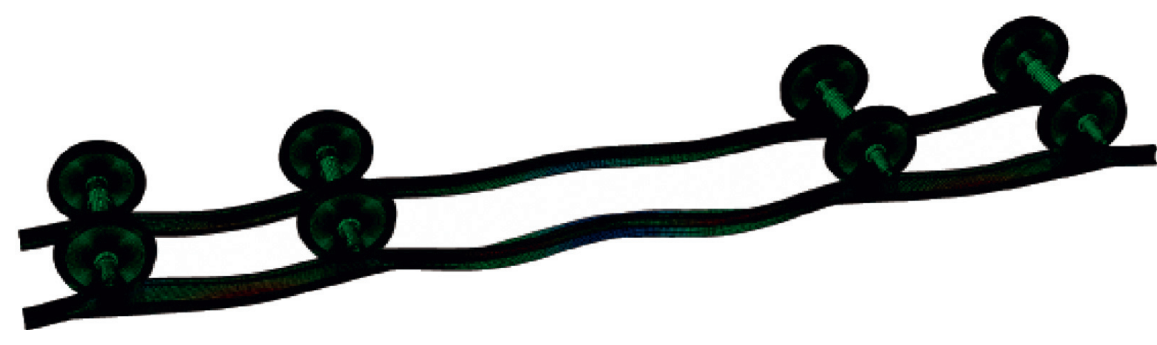

(b)

Figure 12: Natural vibration mode of track structure in Shi-Pan down section. (a) Typical vibration modes of curved track at $75 \mathrm{~Hz}$. (b) Typical vibration modes of curved track at $160 \mathrm{~Hz}$.

calculated to be $26 \mathrm{~Hz}$. Additionally, the triple frequency $(78 \mathrm{~Hz})$ and sextuple-frequency $(156 \mathrm{~Hz})$ are close to the natural vibration frequencies of $75 \mathrm{~Hz}$ and $160 \mathrm{~Hz}$, respectively. Therefore, the vehicle passing incentive excited by track discontinuity support excites the high-order harmonic resonance of the track structure, which leads to rail corrugation. The theory proposed in this paper that corrugation is caused by the high-order harmonic resonance of track structures is proven.

\section{Conclusions}

This paper concerns the causation and growth of the rail corrugation on curved tracks with small radii, where a practical prediction model of rail corrugation growth is proposed. And the following conclusions are obtained. (1) The superharmonic resonance of the track is the key cause of rail corrugation, and this superharmonic resonance is directly excited by the passing excitation induced during the train negotiating the discrete support track. (2) The curve radius, supporting stiffness of fastener, and sleeper spacing are the three critical factors affecting the growth of corrugation. (3) The adjustment of the support stiffness or sleeper spacing leads to fluctuations in the corrugation wavelength and its growth rate, while reducing the support stiffness and the sleeper spacing can suppress the formation of rail corrugation. The above studies coincide well with the conclusions obtained in existing studies and are of great significance to the prevention and maintenance of corrugated wear, while the real-time detection of rail corrugation based on deep learning network $[67,68]$ will be investigated in the future research.

\section{Data Availability}

The data used to support the findings of this study are included within the article.

\section{Conflicts of Interest}

The authors declare that there are no conflicts of interest with respect to the research, authorship, and the publication of this article.

\section{Acknowledgments}

This work was supported by the State Key Laboratory of Rail Traffic Control and Safety, Beijing Jiaotong University, under grant RCS20121ZT003, and it was also supported by the Fundamental Research Funds for the Central Universities in China (grant no. 2020JBZD011).

\section{References}

[1] M. Owais, A. S. Ahmed, G. S. Moussa, and A. A. Khalil, "Design scheme of multiple-subway lines for minimizing passengers transfers in mega-cities transit networks," International Journal of Rail Transportation, pp. 1-24, 2020.

[2] M. Owais, A. S. Ahmed, G. S. Moussa, and A. A. Khalil, "An optimal metro design for transit networks in existing square cities based on non-demand criterion," Sustainability, vol. 12, no. 22, p. 9566, 2020.

[3] M. Owais, A. S. Ahmed, G. S. Moussa, and A. A. Khalil, "Integrating underground line design with existing public transportation systems to increase transit network connectivity: case study in greater cairo," Expert Systems with Applications, vol. 167, 2020.

[4] M. Owais, "Location strategy for traffic emission remote sensing monitors to capture the violated emissions," Journal of Advanced Transportation, vol. 2019, no. 2, pp. 1-9, Article ID 6520818, 2019.

[5] M. Owais, O. Abulwafa, and Y. A. Abbas, "When to decide to convert a roundabout to a signalized intersection: simulation approach for case studies in jeddah and Al-madinah," Arabian Journal for Science and Engineering, vol. 45, no. 10, pp. 7897-7914, 2020. 
[6] X. Feng, H. Zhang, Y. Ding et al., "A review study on traction energy saving of rail transport," Discrete Dynamics in Nature and Society, vol. 9, no. 22, pp. 1611-1617, 2013.

[7] Y. Zhang, Q.-f. Zeng, D. Lei, and X. Wang, "Simulating the effects of noncrossing block sections setting rules on capacity loss of double-track railway line due to the operation of outof-Gauge trains," Discrete Dynamics in Nature and Society, vol. 2016, no. 25, pp. 1-16, Article ID 2319437, 2016.

[8] H. Xiao, S. Yang, H. Wang, and S. X. Wu, "Initiation and development of rail corrugation based on track vibration in metro systems," Proceedings of the Institution of Mechanical Engineers, Part F: Journal of Rail and Rapid Transit, vol. 232, no. 9, pp. 2228-2243, 2018.

[9] A. E. Rahim, M. Enieb, A. A. Khalil et al., "Twin tunnel configuration for Greater Cairo metro line," Computers and Geotechnics, vol. 68, no. 4, pp. 66-77, 2015.

[10] X. Yin and X. Wei, "Development characteristics of inner rail corrugation in small radius curve of Metro," IOP Conference Series: Earth and Environmental Science, vol. 587, no. 1, Article ID 012077, 2020.

[11] S. Yang, Research on generation and development mechanism of rail corrugation based on wheel rail vibration characteristics, PhD thesis, Beijing Jiaotong University, Beijing, China, 2015.

[12] L. Xiaofeng, X. Yang, L. Jia et al., "Fault diagnosis of train axle box bearing based on multi-feature parameters," Discrete Dynamics in Nature and Society, vol. 2015, Article ID 846918, 8 pages, 2015.

[13] M. Owais and M. K. Osman, "Complete hierarchical multiobjective genetic algorithm for transit network design problem," Expert Systems with Applications, vol. 114, pp. 143-154, 2018.

[14] M. Owais, M. K. Osman, and G. Moussa, "Multi-Objective transit route network design as set covering problem," IEEE Transactions on Intelligent Transportation Systems, vol. 17, no. 3, pp. 670-679, 2016.

[15] M. Owais, G. S. Moussa, and K. F. Hussain, "Sensor location model for O/D estimation: multi-criteria meta-heuristics approach," Operations Research, vol. 14, 2019.

[16] M. Owais and T. Hassan, "Incorporating dynamic bus stop simulation into static transit assignment models," International Journal of Civil Engineering, vol. 16, 2016.

[17] M. Owais and A. Alshehri, "Pareto optimal path generation algorithm in stochastic transportation networks," IEEE Access, vol. 8, pp. 58970-58981, 2020.

[18] M. Owais, M. E. Deeb, and Y. A. Abbas, "Distributing portable excess speed detectors in AL riyadh city," International Journal of Civil Engineering, vol. 18, no. 11, 2020.

[19] Y. Wang and T. X. Wu, "The growth and mitigation of rail corrugation due to vibrational interference between moving wheels and resilient track," Vehicle System Dynamics, vol. 58, no. 8, pp. 1257-1284, 2020.

[20] S. L. Grassie and J. Kalousek, "Rail corrugation: characteristics, causes, and treatments," Proceedings of the Institution of Mechanical Engineers, Part F: Journal of Rail and Rapid Transit, vol. 207, no. 1, pp. 57-68, 1993.

[21] S. L. Grassie and J. Kalousek, "Rail corrugation: characteristics, causes, and treatments," Proceedings of the Institution of Mechanical Engineers, Part F: Journal of Rail and Rapid Transit, vol. 223, no. 6, pp. 581-596, 2009.

[22] S. L. Grassie and J. A. Elkins, "Rail corrugation on north American transit systems," Vehicle System Dynamics, vol. 29, no. sup1, pp. 5-17, 1998.
[23] W. J. T. Daniel, R. J. Horwood, P. A. Meehan et al., “Analysis of rail corrugation in cornering," Wear, vol. 265, no. 9-10, pp. 1183-1192, 2008.

[24] E. Tassilly and N. Vincent, "A linear model for the corrugation of rails," Journal of Sound and Vibration, vol. 150, no. 1, pp. 25-45, 1991.

[25] X. Jin, Z. Wen, K. Wang, and W. Zhang, "Effect of a scratch on curved rail on initiation and evolution of rail corrugation," Tribology International, vol. 37, no. 5, pp. 385-394, 2004.

[26] S. L. Grassie, "Corrugation on Australian National: cause measurement and rectification," Railway in Action; Preprints of Papers, pp. 188-192, The Institution of Engineers, Australia, 1989.

[27] D. R. Ahlbeck and L. E. Daniels, "Investigation of rail corrugations on the baltimore metro," Wear, vol. 144, no. 1-2, pp. 197-210, 1991.

[28] J. J. Kalker and K. L. Johnson, "Three-dimensional elastic bodies in rolling contact," Journal of Applied Mechanics, vol. 60, no. 1, p. 255, 1993.

[29] P. T. Torstensson and M.. Schilke, "Rail corrugation growth on small radius curves-measurements and validation of a numerical prediction model," Wear, vol. 303, no. 1-2, pp. 381-396, 2013.

[30] W. Ping and X. Liu, "Torsional vibration of wheelsets and curved rail corrugations," Journal of Southwest Jiaotong University, vol. 31, no. 1, pp. 58-62, 1996.

[31] J. Zhang, "Rail corrugation at high frequency wheel/rail interaction," Tribiology, vol. 23, no. 2, pp. 128-131, 2003.

[32] Y. Suda, "The mechanics for self-generation of corrugations," Tribiology, vol. 38, no. 12, pp. 1553-1563, 1993.

[33] B. Kurzeck, "Combined friction induced oscillations of wheelset and track during the curving of metros and their influence on corrugation," Wear, vol. 271, no. 1-2, pp. 299-310, 2011.

[34] G. X. Chen, Z. R. Zhou, H. Ouyang, X. S. Jin, M. H. Zhu, and Q. Y. Liu, "A finite element study on rail corrugation based on saturated creep force-induced self-excited vibration of a wheelset-track system," Journal of Sound and Vibration, vol. 329, no. 22, pp. 4643-4655, 2010.

[35] W. P. Hu, P. Wang, G. X. Chen et al., "Experimental study on corrugation of a sliding surface caused by frictional self-excited vibration," Tribology Transactions, vol. 59, no. 1, pp. 8-16, 2016.

[36] L. Zhang and W. Zhang, "Formation mechanism and reproduction test of wheel rail corrugation," Journal of Southwest Jiaotong University, vol. 40, no. 4, pp. 435-439, 2005.

[37] X. JIN and Z. WEN, "Rail corrugation formation studied with a full-scale test facility and numerical analysis," Proceedings of the Institution of Mechanical Engineers, Part J: Journal of Engineering Tribology, vol. 221, no. 6, pp. 675-698, 2007.

[38] S. Ding, "Preface of special research on abnormal corrugation of rail in Urban Rail Transit," Urban Rapid Railway Transit, vol. 24, no. 3, p. 1, 2011.

[39] C. Zhao, P. Wang, X. Sheng, and D. Meng, "Theoretical simulation and experimental investigation of a rail damper to minimize short-pitch rail corrugation," Mathematical Problems in Engineering, vol. 2017, pp. 1-14, 2017.

[40] N. Correa, O. Oyarzabal, E. G. Vadillo et al., "Rail corrugation development in high speed lines," Wear, vol. 271, no. 9-10, pp. 2438-2447, 2011.

[41] A. Wang, Z. Wang, P. Zhang et al., "Mechanism and control of rail corrugation," Material Development and Response, vol. 29, no. 6, pp. 6-15, 2014. 
[42] J. Maes and H. Sol, "A double tuned rail damper-increased damping at the two first pinned-pinned frequencies," Journal of Sound and Vibration, vol. 267, no. 3, pp. 721-737, 2003.

[43] B. E. Croft, C. J. C. Jones, and D. J. Thompson, "Modelling the effect of rail dampers on wheel-rail interaction forces and rail roughness growth rates," Journal Sound Vibration, vol. 323, no. 1-2, pp. 17-32, 2009.

[44] A. Wang, Z. Wang, Z. Zhao et al., "Effects of track stiffness and tuned rail damper on rail roughness growth and rail vibration levels on metro system," Notes on Numerical Fluid Mechanics and Multidisciplinary Design, vol. 126, pp. 667-674, 2015.

[45] T. X. Wu, "Effects on short pitch rail corrugation growth of a rail vibration absorber/damper," Wear, vol. 271, no. 1-2, pp. 339-348, 2011.

[46] Y. Suda and H. Komine, "Contact vibration with high damping alloy,” Wear, vol. 191, no. 1-2, pp. 72-77, 1996.

[47] H. Ilias, "The influence of railpad stiffness on wheelset/track interaction and corrugation growth," Journal of Sound and Vibration, vol. 227, no. 5, pp. 935-948, 1999.

[48] M. Tomeoka, N. Kabe, M. Tanimoto, E. Miyauchi, and M. Nakata, "Friction control between wheel and rail by means of on-board lubrication," Wear, vol. 253, no. 1-2, pp. 124-129, 2002.

[49] H. Chen, S. Fukagai, Y. Sone et al., "Assessment of lubricant applied to wheel/rail interface in curves," Wear, vol. 314, no. 1-2, pp. 228-235, 2014.

[50] C. P. Sharma and A. Srikantha Phani, "Stability analysis of onboard friction modifier systems at the wheel-rail interface," Journal of Vibration and Acoustics, vol. 137, no. 5, Article ID 051007, 2015.

[51] A. R. Valdivia, "A linear dynamic wear model to explain the initiating mechanism of corrugation," Vehicle System Dynamics, vol. 17, no. sup1, pp. 493-496, 1988.

[52] K. Hempelmann and K. Knothe, "An extended linear model for the prediction of short pitch corrugation," Wear, vol. 191, no. 1-2, pp. 161-169, 1996.

[53] K. Hempelmann, F. Hiss, K. Knothe, and B. Ripke, "The formation of wear patterns on rail tread," Wear, vol. 144, no. 1-2, pp. 179-195, 1991.

[54] S. Muller, "A linear wheel-track model to predict instability and short pitch corrugation," Journal of Sound and Vibration, vol. 227, no. 5, pp. 899-913, 1999.

[55] S. Muller, "A linear wheel-rail model to investigate stability and corrugation on straight track," Wear, vol. 243, pp. 122$132,2000$.

[56] C. Andersson and A. Johansson, "Prediction of rail corrugation generated by three-dimensional wheel-rail interaction," Wear, vol. 257, no. 3-4, pp. 423-434, 2004.

[57] I. Gomaz and E. G. Vadillo, "A linear model to explain short pitch corrugation on rails," Wear, vol. 255, pp. 1127-1142, 2003.

[58] L. Du, W. Liu, W. Liu et al., "Study on frequency response characteristics of torsional vibration of curved rail," Journal of Vibration Engineering, no. 4, pp. 644-653, 2018.

[59] W. Liu, L. Du, W. Liu et al., "Study on the dynamic response of a curved railway track subjected to harmonic loads based on periodic structure theory," Proceedings of the Institution of Mechanical Engineers Part F Journal of Rail \& Rapid Transit, vol. 232, no. 7, pp. 2639-2644, 2017.

[60] W. N. Liu, L. X. Ma, B. L. Jiang et al., "Generalized wave number method for dynamic response analysis of floating slab track," China Railway Sciences, vol. 37, no. 001, pp. 31-38, 2016.
[61] J. F. Archard, "Contact and rubbing of flat surfaces," Journal of Applied Physics, vol. 24, no. 8, pp. 981-988, 1953.

[62] Z. Zeng, K. Zhu, X. He, W. Xu, L. Chen, and P. Lou, "Random vibration analysis of train moving over slab track on bridge under track irregularities and earthquakes by pseudoexcitation method," Discrete Dynamics in Nature and Society, vol. 2015, Article ID 436567, 22 pages, 2015.

[63] S. L. Grassie, R. W. Gregory, and K. L. Johnson, "The dynamic response of railway track to high frequency lateral excitation," Journal of Mechanical Engineering Science, vol. 24, no. 2, pp. 91-95, 1982.

[64] V. Petrenko, "Simulation of railway vehicle dynamics in universal mechanism software," Procedia Engineering, vol. 134, pp. 23-29, 2016.

[65] J. Piotrowski and W. Kik, "A simplified model of wheel/rail contact mechanics for non-Hertzian problems and its application in rail vehicle dynamic simulations," Vehicle System Dynamics, vol. 46, no. 1-2, pp. 27-48, 2008.

[66] E. G. Vadillo, J. Tárrago, G. G. Zubiaurre, and C. A. Duque, "Effect of sleeper distance on rail corrugation," Wear, vol. 217, no. 1, pp. 140-145, 1998.

[67] M. Owais, G. S. Moussa, and K. F. Hussain, "Robust deep learning architecture for traffic flow estimation from a subset of link sensors," Journal of Transportation Engineering, vol. 146, no. 1, pp. 04019055.1-04019055.13, 2020.

[68] G. S. Moussa and M. Owais, "Pre-trained deep learning for hot-mix asphalt dynamic modulus prediction with laboratory effort reduction," Construction and Building Materials, vol. 2020 , p. $265,2020$. 